Article

\title{
Effect of Steel Fibers on the Hysteretic Performance of Concrete Beams with Steel Reinforcement-Tests and Analysis
}

\author{
Violetta K. Kytinou ${ }^{\mathbb{D}}$, Constantin E. Chalioris* ${ }^{\mathbb{D}}$, Chris G. Karayannis and Anaxagoras Elenas \\ Laboratory of Reinforced Concrete and Seismic Design of Structures, Civil Engineering Department, \\ Faculty of Engineering, Democritus University of Thrace (D.U.Th.), 67100 Xanthi, Greece; \\ vkytinou@civil.duth.gr (V.K.K.); karayan@civil.duth.gr (C.G.K.); elenas@civil.duth.gr (A.E.) \\ * Correspondence: chaliori@civil.duth.gr; Tel.: +30-2541-079-632
}

Received: 5 June 2020; Accepted: 29 June 2020; Published: 29 June 2020

\begin{abstract}
The use of fibers as mass reinforcement to delay cracking and to improve the strength and the post-cracking performance of reinforced concrete $(\mathrm{RC})$ beams has been well documented. However, issues of common engineering practice about the beneficial effect of steel fibers to the seismic resistance of RC structural members in active earthquake zones have not yet been fully clarified. This study presents an experimental and a numerical approach to the aforementioned question. The hysteretic response of slender and deep steel fiber-reinforced concrete (SFRC) beams reinforced with steel reinforcement is investigated through tests of eleven beams subjected to reversal cyclic loading and numerical analysis using 3D finite element (FE) modeling. The experimental program includes flexural and shear-critical SFRC beams with different ratios of steel reinforcing bars $(0.55 \%$ and $1.0 \%$ ), closed stirrups (from 0 to $0.5 \%$ ), and fibers with content from 0.5 to $3 \%$ per volume. The developed nonlinear FE numerical simulation considers well-established relationships for the compression and tensional behavior of SFRC that are based on test results. Specifically, a smeared crack model is proposed for the post-cracking behavior of SFRC under tension, which employs the fracture characteristics of the composite material using stress versus crack width curves with tension softening. Axial tension tests of prismatic SFRC specimens are also included in this study to support the experimental project and to verify the proposed model. Comparing the numerical results with the experimental ones it is revealed that the proposed model is efficient and accurately captures the crucial aspects of the response, such as the SFRC tension softening effect, the load versus deformation cyclic envelope and the influence of the fibers on the overall hysteretic performance. The findings of this study also reveal that SFRC beams showed enhanced cyclic behavior in terms of residual stiffness, load-bearing capacity, deformation, energy dissipation ability and cracking performance, maintaining their integrity through the imposed reversal cyclic tests.
\end{abstract}

Keywords: steel fiber-reinforced concrete (SFRC); cyclic tests; reinforced concrete; direct tension tests; hysteretic response; tension softening; smeared crack model; residual stiffness; finite element (FE) analysis; shear; flexure; numerical analysis

\section{Introduction}

Short discrete fibers are used as mass reinforcement in concrete structural members to enhance tensile characteristics and to control crack width by the crack-bridging phenomenon observed at a local crack. The structural advances of fiber-reinforced cement-based members depend mainly on the content and the geometrical and mechanical properties of the fibers. Each fiber type influences in some particular function acting as crack arrestors due to their strength, bond, and pullout mechanisms across 
a crack surface. The addition of fibers to concrete has been shown to increase its toughness significantly and to promote more ductile material behavior [1-6]. The incorporation of randomly distributed short steel fibers has been developed as an alternative reinforcement technique to improve the brittle tensional failure and poor cracking performance of concrete by the debonding and pullout process of the fibers [7-9]. For this reason, deformed steel fibers with hooked ends exhibit anchoring action, providing increased bond characteristics that leads to a crucial enhancement of the post-cracking response, improving the energy-absorbing capability [10-12].

Reinforced concrete (RC) structural members with a low shear span-to-depth ratio, such as deep beams, are shear-vulnerable exhibiting brittle failure due to the low tensile properties of concrete [13]. The favorable influence of fiber-reinforced concrete inspired researchers to study the application of fibers in shear-critical RC beams instead of conventional transverse steel reinforcement [14-16]. In beams, the addition of steel fibers improves the concrete's diagonal tension capacity, leading to increased shear resistance, which can promote flexural failure and ductility [17,18]. Although the full replacement of conventional steel stirrups with fibers proved to be rather difficult, at least a partial replacement of closed stirrups with steel fibers leading to desirable reduce of conventional reinforcement congestion could be possible under certain circumstances [19-21]. The replacement of steel stirrups is important in shear-deficient RC joints [22-25], columns [26,27], deep [28] and torsional beams [29], where design criteria usually require a high amount of transverse reinforcement leading to dense placing of stirrups or the installation of cumbersome reinforcing systems. In this direction, a significant contribution is the recent analytical models that have been proposed to predict the shear capacity of steel fiber-reinforced concrete (SFRC) beam with [30,31] or without stirrups [32-34].

Reinforced concrete is capable of bearing some tensile stresses between cracks; this effect is called tension stiffening and is responsible for increased tensile stiffness in the RC member before the yielding of reinforcement [35]. Rigidity, deflections and crack widths may be greatly affected by this effect under the service limit state. The inclusion of steel fibers in the concrete matrix can reduce control crack splitting and significantly enhances residual stiffness, as SFRC can bear tensile stresses along the cracks [36-40]. However, the very restricted usage of SFRC in structural applications is mostly related to the difficulties in determining accurate and logical approaches that represent and estimate the performance of the material in either service or ultimate limit state. At flexure ultimate limit state, the tensile strength of SFRC members is usually disregarded [41,42]. Nevertheless, the member is stiffer as SFRC can bear tensile stresses both across cracks and among them. Thus, as strain increases and cracks coalesce, adequate residual tensile stresses are still developed since SFRC utilizes the fiber crack bridging effect, the tension stiffening attributed to steel reinforcement bond with concrete and the fracture mechanics of SFRC. This residual stiffness must be included in the calculations for the design of SFRC structural members, as it has been observed that the residual stresses get increased by adding higher amounts of steel fibers in the concrete mixture [43,44].

It is known that steel fibers and conventional steel reinforcing bars with stirrups are usually combined. In such cases, the tensile stresses that are being developed at a crack are distributed to the reinforcing bars and steel fibers bridging the crack. This way, the added steel fibers enhance the residual stiffness, provide crack control and enables the usage of higher strength steel reinforcement while retaining the control of crack widths based on the type and amount of steel fibers added [45,46]. These effects have become vital in determining cracking processes at service loads and in developing accurate constitutive models of cracked SFRC, which can be used in an analysis to predict member behavior $[47,48]$.

It is recognized that the effective design of SFRC structures against complex external actions, such as earthquake, fatigue, explosion, and other types of loads, require a clear understanding of SFRC's mechanical behavior under monotonic and cyclic loads. Cyclic loading is one of the most complex loading conditions, both in structural performance and from a modeling point of view. Researchers have studied the fatigue life of fiber-reinforced high-strength concretes to determine the number of cycles that the specimen can withstand $[49,50]$. Others have studied cyclic tensile behavior of SFRC to 
reveal the underlying damage mechanism and SFRC specimens subjected to cyclic compressive load to a variety of high-stress range and high strain rate [51-53]. There are only a few cyclic experimental tests on SFRC beams under flexure [54-59]. Besides, while there is extensive research on the shear behavior of SFRC subject to monotonic loading, there is minimal research on the behavior of shear-critical SFRC structural members subject to reverse cyclic loading [60-62].

From the above literature review, it can be summarized that although some attempts have been made to capture the cyclic response of SFRC, broad experimental studies on the reverse cyclic behavior of SFRC have still been limited. The cyclic stress-strain relation and the damage evolution law of SFRC materials are some of the critical aspects in uncovering the realistic failure process as well as probing the variation of the structural responses of SFRC structures.

The present study aims to contribute to the ongoing research on SFRC by examining the significance of considering the tension softening and residual stiffness effect in SFRC beams subjected to reverse cyclic loading failing in flexure or shear. The precise definition of how this effect progresses with the number of cycles has not yet been adequately investigated as far as SFRC is concerned. For this purpose, a research program has been carried out herein, combining experimental investigation and numerical modeling. Precise finite element (FE) simulation that has been established with test data enables to explore even more the parameters affecting and to solve difficult structural problems [63-65].

The experimental part of this study includes two series of concrete beams with conventional steel reinforcing bars, stirrups, and short steel fibers. The first series consists of two slender SFRC beams tested under displacement control cyclic loading conducted by Chalioris et al. [66]. The second series includes nine deep SFRC beams subjected to a force control cyclic reversal loading for the purposes of this study. This test project brings new data concerning the improvement of the hysteretic behavior of realistic beams under reversal loading due to the addition of steel fibers. That might broaden the application of SFRC to structures in regions with high seismic activity.

Furthermore, a computationally efficient simulation using ABAQUS [67] software that takes into account the nonlinearities of the SFRC is also presented. The developed nonlinear FE analysis allows for an accurate prediction of the overall hysteretic response of realistic SFRC members. Comparisons between test and numerical results showed the feasibility of the proposed approach to simulate the response of flexural and shear-critical SFRC beams subjected to cyclic deformations. The effect of steel fibers on the overall performance and cracking behavior is also presented and discussed.

\section{Materials and Methods}

\subsection{Experimental Investigation}

The experimental part of this study includes two series of concrete beams with conventional steel reinforcing bars, stirrups, and short steel fibers. The first series consists of two slender SFRC beams tested under displacement control cyclic loading that was conducted by Chalioris et al. [66]. The second series includes nine deep SFRC beams subjected to a force control cyclic reversal loading for the purposes of this study. Details of the beam specimens are presented in this section.

\subsubsection{Characteristics of the Beam Specimens}

Beams are sorted in three groups ("FL", "SH-s" and "SH") as shown in Table 1 and described below: 
Table 1. Properties of the tested beams.

\begin{tabular}{|c|c|c|c|c|c|c|c|c|c|c|c|c|c|c|}
\hline \multirow[b]{2}{*}{ Group } & \multirow[b]{2}{*}{ Beam Name } & \multicolumn{5}{|c|}{ Geometrical Data } & \multicolumn{5}{|c|}{ Steel Reinforcement (Bars and Stirrups) } & \multicolumn{3}{|c|}{ Steel Fiber Characteristics * } \\
\hline & & $\begin{array}{c}b \\
(\mathrm{~mm})\end{array}$ & $\begin{array}{c}h \\
(\mathrm{~mm})\end{array}$ & $\begin{array}{c}d \\
(\mathrm{~mm})\end{array}$ & $\begin{array}{c}a_{s} \\
(\mathrm{~mm})\end{array}$ & $a_{s / d}$ & $\begin{array}{c}A_{s 1}=A_{s 2} \\
(\varnothing \text { in } \mathrm{mm})\end{array}$ & $\begin{array}{c}\rho_{l 1}=\rho_{l 2} \\
\mathbf{( \% )}\end{array}$ & $\begin{array}{c}\emptyset_{w} / \mathrm{s} \\
(\mathrm{mm} / \mathrm{mm})\end{array}$ & $\begin{array}{l}\rho_{w} \\
(\%)\end{array}$ & $\begin{array}{c}f_{y} \\
\text { (MPa) }\end{array}$ & $\begin{array}{l}V_{S F} \\
(\%)\end{array}$ & $\begin{array}{c}l_{S F} / d_{S F} \\
(\mathrm{~mm} / \mathrm{mm})\end{array}$ & $F$ \\
\hline \multirow{2}{*}{ “FL" } & FL0.3 & 200 & 200 & 170 & 1000 & 5.9 & $3 \varnothing 12$ & 1.00 & $\varnothing 8 / 200$ & 0.25 & 590 & 1.00 & $44 / 1.0$ & 0.3 \\
\hline & FL1.0 & 200 & 200 & 170 & 1000 & 5.9 & $3 \varnothing 12$ & 1.00 & $\varnothing 8 / 200$ & 0.25 & 590 & 3.00 & $44 / 1.0$ & 1.0 \\
\hline \multirow{4}{*}{ “SH-s" } & SH0-s37 & 100 & 300 & 275 & 550 & 2.0 & $3 \varnothing 8$ & 0.55 & $\varnothing 8 / 275$ & 0.37 & 575 & - & - & - \\
\hline & SH0-s50 & 100 & 300 & 275 & 550 & 2.0 & $3 \varnothing 8$ & 0.55 & $\varnothing 8 / 200$ & 0.50 & 575 & - & - & - \\
\hline & SH0.3-s37 & 100 & 300 & 275 & 550 & 2.0 & $3 \varnothing 8$ & 0.55 & $\varnothing 8 / 275$ & 0.37 & 575 & 0.50 & $60 / 0.8$ & 0.3 \\
\hline & SH0.3-s50 & 100 & 300 & 275 & 550 & 2.0 & $3 \varnothing 8$ & 0.55 & $\varnothing 8 / 200$ & 0.50 & 575 & 0.50 & $60 / 0.8$ & 0.3 \\
\hline \multirow{5}{*}{ "SH" } & SH0 & 100 & 300 & 275 & 550 & 2.0 & $3 \varnothing 8$ & 0.55 & - & - & 575 & - & - & - \\
\hline & SH0.3 & 100 & 300 & 275 & 550 & 2.0 & $3 \varnothing 8$ & 0.55 & - & - & 575 & 0.50 & $60 / 0.8$ & 0.3 \\
\hline & SH0.4 & 100 & 300 & 275 & 550 & 2.0 & $3 \varnothing 8$ & 0.55 & - & - & 575 & 0.75 & $60 / 0.8$ & 0.4 \\
\hline & SH0.6 & 100 & 300 & 275 & 550 & 2.0 & $3 \varnothing 8$ & 0.55 & - & - & 575 & 1.00 & $60 / 0.8$ & 0.6 \\
\hline & SH0.8 & 100 & 300 & 275 & 550 & 2.0 & $3 \varnothing 8$ & 0.55 & - & - & 575 & 1.50 & $60 / 0.8$ & 0.8 \\
\hline
\end{tabular}

${ }^{*}$ Hooked steel fibers with $f_{S F}=1000 \mathrm{MPa}$. 
Group "FL" includes the two slender beams ( $2500 \mathrm{~mm}$ long) failed in flexure (specimens FL0.3 and FL1.0) containing 1\% and 3\% steel fibers per volume fraction, $V_{S F}$, respectively, that correspond to $80 \mathrm{~kg}$ and $240 \mathrm{~kg}$ per cubic meter of concrete, respectively. The added steel fibers are hooked-ended with a length to diameter ratio (aspect ratio) of $l_{S F} / d_{S F}=44 \mathrm{~mm} / 1 \mathrm{~mm}=44$, a bond factor of $\beta=0.75$ and, therefore, the fiber factor of beams FL0.3 and FL1.0 is $F=0.3$ and 1.0, respectively. The geometrical and the reinforcement characteristics of these flexural beams are presented in Table 1 and further details can also be found in the recent study of Chalioris et al. [66].

All deep beams (nine shear-critical specimens) are $1600 \mathrm{~mm}$ long, have the same width to height ratio $b / h=100 / 300 \mathrm{~mm}$, effective depth $d=275 \mathrm{~mm}$, shear span $a_{s}=550 \mathrm{~mm}$, shear span to effective depth ratio $a_{S} / d=2$ and three longitudinal steel reinforcing bars with a diameter of $8 \mathrm{~mm}$ at the top and at the bottom with geometrical longitudinal reinforcement ratio $\rho_{l 1}=\rho_{l 2}=0.55 \%$ and $f_{y}=575 \mathrm{MPa}$. Deep beams are sorted in two groups "SH-s" and "SH", with and without closed steel stirrups, respectively.

Group "SH-s" includes four deep beams (specimens SH0-s37, SH0-s50, SH0.3-s37 and SH0.3-s50) with stirrups of $8 \mathrm{~mm}$ diameter at a uniform spacing of 275 and $200 \mathrm{~mm}$ that corresponds to a geometrical web (transverse) reinforcement ratio of $\rho_{w}=0.37 \%$ (specimens SH0-s37 and SH0.3-s37) and $\rho_{w}=0.50 \%$ (specimens SH0-s50 and SH0.3-s50), respectively. Beams SH0-s37 and SH0-s50 are made of plain concrete (reference specimens), whereas beams SH0.3-s37 and SH0.3-s50 contain steel fibers with $V_{S F}=0.5 \%$.

Group "SH" consists of five deep beams without stirrups (specimens SH0, SH0.3, SH0.4, SH0.6 and SH0.8) that contain steel fibers with $V_{S F}=0$ (plain concrete reference beam), $0.5 \%, 0.75 \%, 1.0 \%$ and $1.5 \%$, respectively.

The steel fibers added in the deep beams are hooked ended with a length to diameter ratio (aspect ratio) of $l_{S F} / d_{S F}=60 \mathrm{~mm} / 0.8 \mathrm{~mm}=75$, bond factor $\beta=0.75$ and, therefore, the fiber factor of

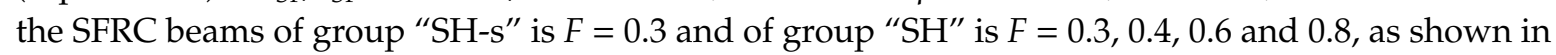
Table 1. Geometrical and reinforcement characteristics of all the examined beams are also summarized in Table 1 and illustrated in Figure 1. Details concerning the preparation stages, the mixture procedure and the curing of steel fiber reinforced concrete specimens can be found in [66].

\subsubsection{Test Rig and Loading Histories}

Beams were imposed to full-cycle deformations and subsequently to increasing load till failure. The test setup is shown in Figure $1 \mathrm{a}, \mathrm{b}$ for the slender and the deep beams, respectively. A four-point-bending test setup was implemented for the cyclic reversal loading of the beams that were simply edge-supported on roller supports $2200 \mathrm{~mm}$ (slender beams) and $1450 \mathrm{~mm}$ (deep beams) apart in a rigid laboratory frame.

The imposed load was applied in two points in the mid-span of the beams and therefore the shear span, $a_{s}$, is equal to $1000 \mathrm{~mm}$ (slender beams) and $550 \mathrm{~mm}$ (deep beams) with span-to-depth ratio: $a_{s} / d=5.9$ (slender beams) and 2.0 (deep beams). The load was measured by a load cell with $0.05 \mathrm{kN}$ accuracy and net midspan deformations by LVDTs with $0.01 \mathrm{~mm}$ accuracy that were placed in the midspan of the beams and the supports. The load and corresponding deflection measurements were recorded continuously during the performed cyclic tests. 


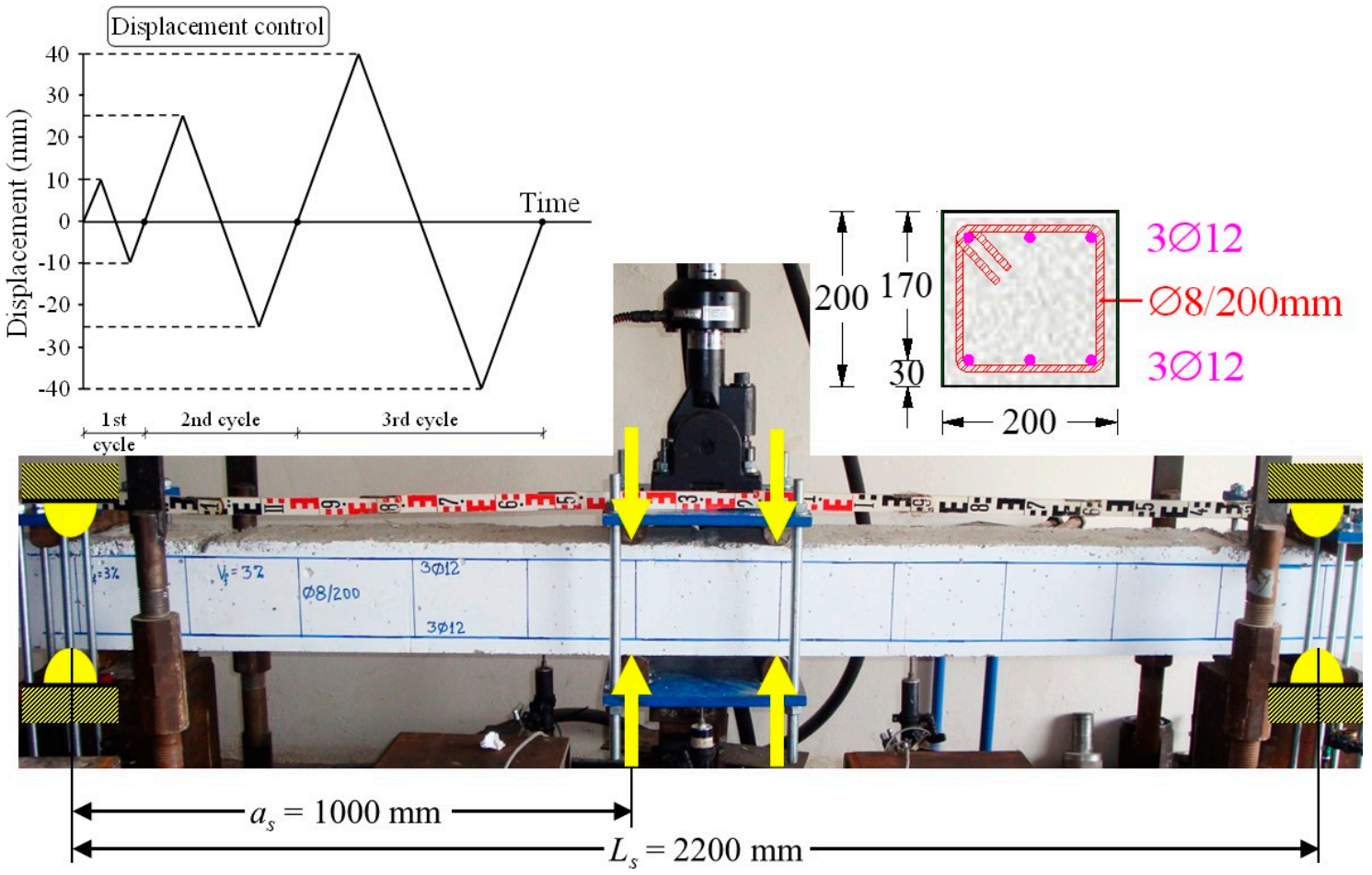

(a)

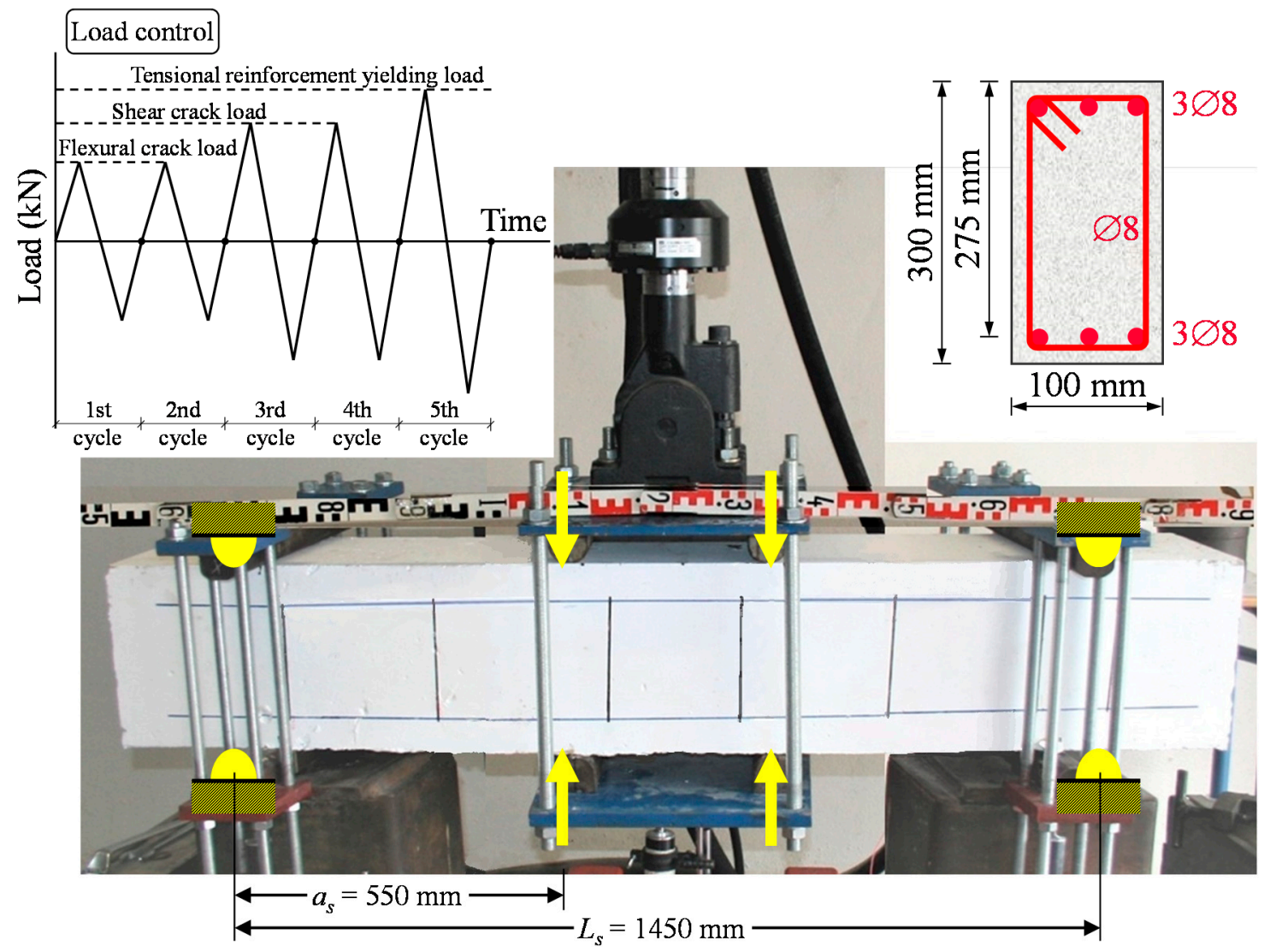

(b)

Figure 1. Geometry, reinforcement and cyclic reversal loading sequence of the tested specimens (dimensions in mm): (a) slender (flexural) beams; (b) deep (shear-critical) beams. 
Beams of group "FL" (flexural specimens) were tested under increasing cyclic loading history that includes three loading steps as shown in Figure 1a. The loading history of the deep beams of group "SH" (specimens without stirrups) and the beams of group "SH-s" (specimens with stirrups) includes three and five full loading cycles, respectively, as shown in Figure 1b. The first two loading cycles correspond to the load for the initiation of the flexural crack, the next two to the load for the onset of the inclined shear cracking and the last one almost to the load for the steel yielding of the tension bars of the reference beams SH0, SH0-s37 and SH0-s50 (specimens without steel fibers).

\subsubsection{Properties of the SFRC}

The plain concrete and SFRC mixture used consisted of an ordinary general-purpose Portland-type cement (type CEM II $32.5 \mathrm{~N}$, Greek type pozzolan cement with $10 \%$ fly ash), high fineness modulus sand, crushed stone aggregates with a maximum size of $16 \mathrm{~mm}$ (for the slender beams of group "FL") and $9.5 \mathrm{~mm}$ (for the deep beams of groups "SH-s" and "SH") and a water-to-cement ratio of 0.55 and 0.57 , respectively. Uniaxial compression and tension tests were also performed to measure the compressive strength and the full tensile behavioral curves of the SFRC mixtures at the day of the cyclic tests of the beams (after 28 days of curing).

Three standard concrete cylinders with dimensions diameter to height $=150 / 300 \mathrm{~mm}$ were cast from each plain concrete and SFRC mixture and tested under axial compression using a universal testing machine (UTM) with an ultimate capacity of $3000 \mathrm{kN}$. The average compressive strength of the concrete without steel fibers is $27 \mathrm{MPa}$, whereas the average compressive strength, $f_{c, S F}$, of each SFRC beam is presented in Table 2.

Table 2. Compressive and tensile properties of the steel fiber-reinforced concrete (SFRC) of each tested beam.

\begin{tabular}{cccccccccc}
\hline Group & $\begin{array}{c}\text { Beam } \\
\text { Name }\end{array}$ & $\begin{array}{c}E_{c}=E_{t, S F} \\
(\mathbf{G P a})\end{array}$ & $\begin{array}{c}f_{c, S F} \\
\mathbf{( M P a})\end{array}$ & $\begin{array}{c}\varepsilon_{c u, S F} \\
(\mathbf{m m} / \mathbf{m})\end{array}$ & $\begin{array}{c}f_{t, S F} \\
(\mathbf{M P a})\end{array}$ & $k_{f}$ & $\begin{array}{c}G_{f, S F} \\
(\mathbf{N} / \mathbf{m m})\end{array}$ & $\begin{array}{c}\varepsilon_{t o, S F} \\
(\mathbf{m m} / \mathbf{m})\end{array}$ & $k_{w}$ \\
\hline \multirow{2}{*}{ "FL" } & FL0.3 & 29.336 & 25.51 & 3.59 & 3.30 & 0.19 & 2.001 & 0.113 & 0.01 \\
& FL1.0 & 30.442 & 27.25 & 8.47 & 4.39 & 0.43 & 8.561 & 0.144 & 0.01 \\
\hline \multirow{2}{*}{ "SH-s" } & SH0.3-s37 & 30.055 & 28.76 & 3.43 & 2.39 & 0.22 & 0.655 & 0.080 & 0.04 \\
& SH0.3-s50 & 30.055 & 28.76 & 3.43 & 2.39 & 0.22 & 0.655 & 0.080 & 0.04 \\
\hline \multirow{2}{*}{ "SH" } & SH0.3 & 30.055 & 28.76 & 3.43 & 2.39 & 0.22 & 0.601 & 0.080 & 0.04 \\
& SH0.4 & 30.264 & 29.64 & 4.33 & 2.44 & 0.33 & 0.892 & 0.081 & 0.04 \\
& SH0.6 & 30.474 & 30.52 & 5.33 & 2.69 & 0.40 & 1.397 & 0.088 & 0.04 \\
& SH0.8 & 30.893 & 32.27 & 7.64 & 2.79 & 0.57 & 2.084 & 0.090 & 0.04 \\
\hline
\end{tabular}

Concerning the tensile behavior of SFRC, three prismatic specimens were cast from each SFRC mixture and tested under axial tension. Figure 2 illustrates the geometry of the specimens and the direct tension test setup. The extension rate was $0.02 \mathrm{~mm} / \mathrm{m} / \mathrm{sec}$ and tensile deformations and crack width were monitored through four LVDTs with $0.001 \mathrm{~mm}$ accuracy that were placed symmetrically on two steel hoops fixed on the wide edges of the specimen. It is noted that tensile cracking and final failure occurred in the middle of the gauge length area of the SFRC notched specimens, away from the edge-mounted clamps, as shown in Figure 2.

The experimentally measured stress versus crack width behavior of each SFRC mixture under direct tension are presented in Figure 3a,b for the slender and the deep beams, respectively. For comparison reasons, the predictions of the proposed smeared crack tensional model in stress versus crack width curves for each SFRC beam are also illustrated in Figure $3 \mathrm{a}, \mathrm{b}$ and compared the test results. The initial tensile behavior before cracking was elastic and linear to the point of the SFRC tensile strength, $f_{t, S F}$, with elastic modulus under tension, $E_{t, S F}$ (see also Table 2). The main SFRC variables derived from the tests and the proposed model are also presented in Table 2 for each beam. 


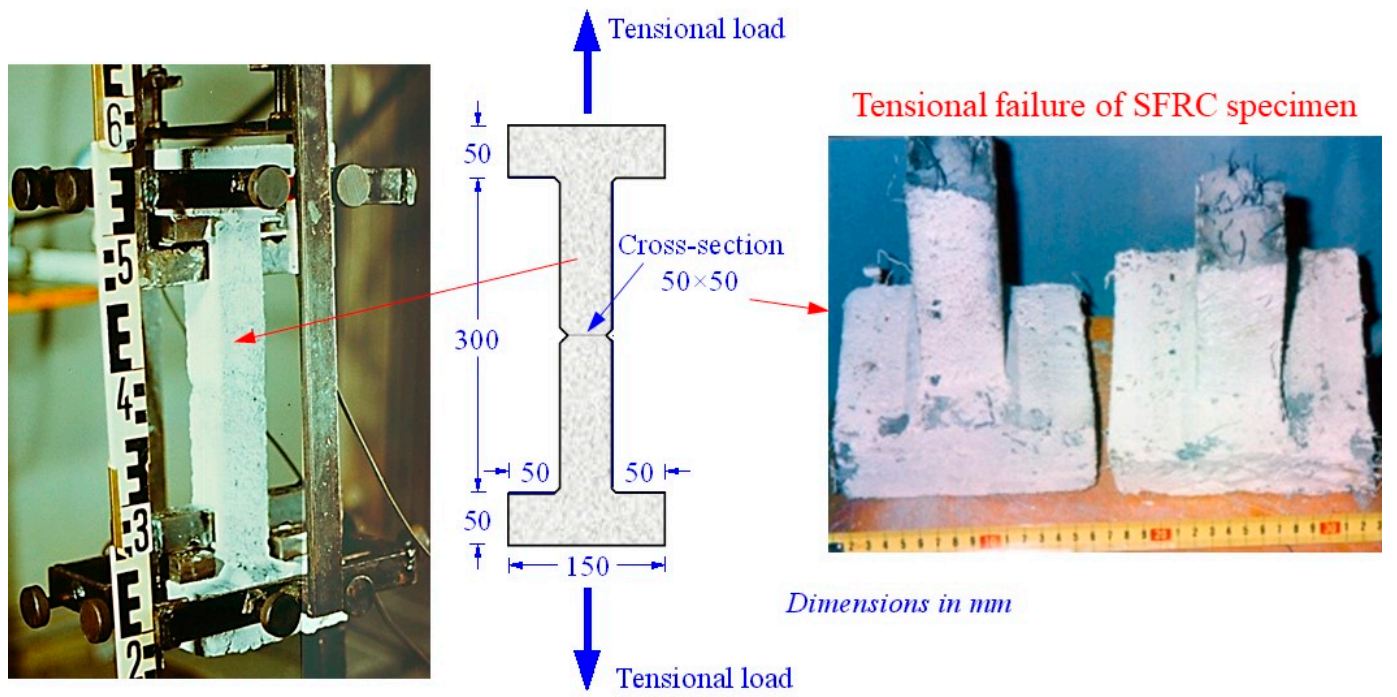

Figure 2. Prismatic SFRC specimen tested and failed under axial tension test.
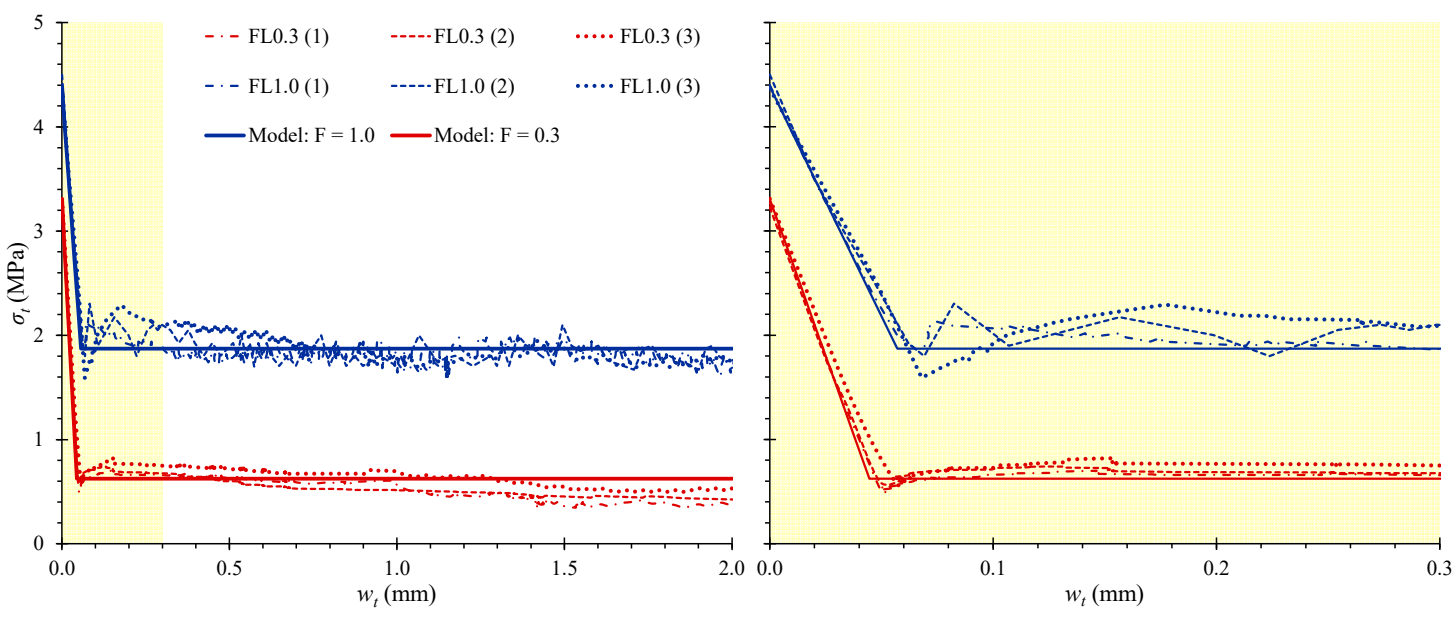

(a)
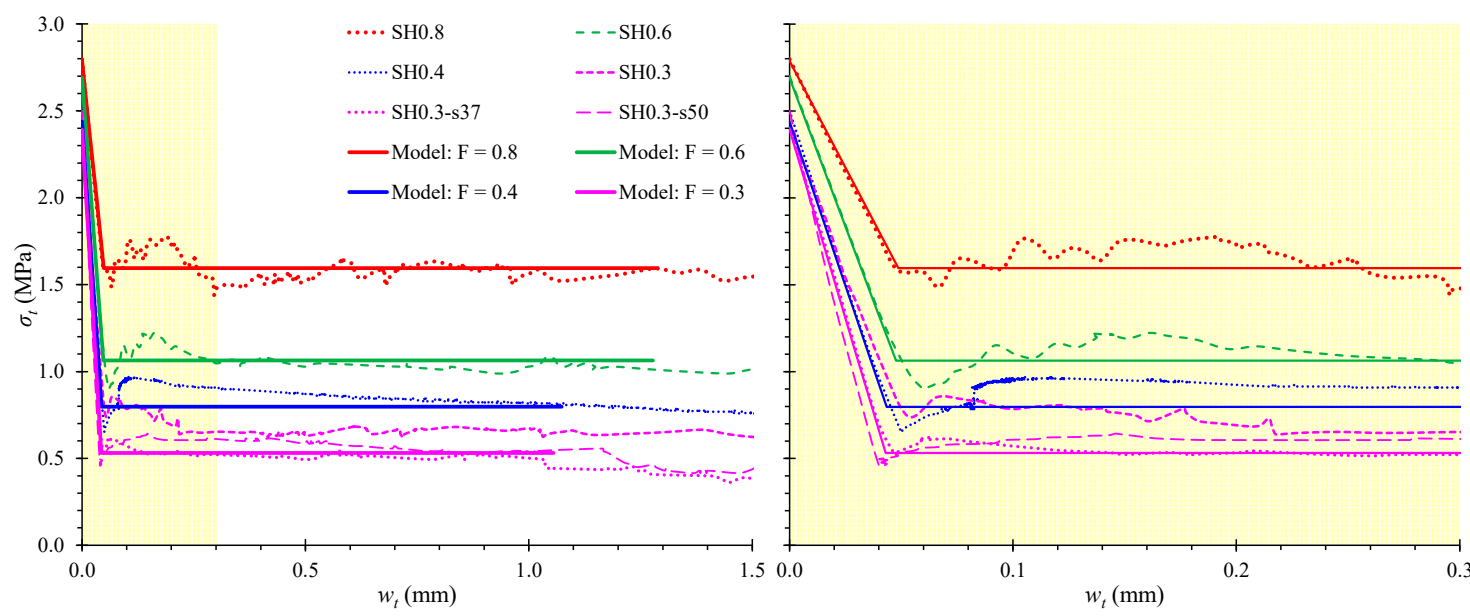

(b)

Figure 3. Tensional stress versus crack width $\left(\sigma_{t}-w_{t}\right)$ behavioral curves obtained from axial direct tension tests and predicted from the proposed model: (a) SFRC mixtures of the slender beams (three tensional specimens from each SFRC mixture); (b) SFRC mixtures of the deep beams. 
The experimental results of the direct tension tests indicate that steel fibers substantially influence the tensile behavior after cracking. The descending post-peak part of the tensile response, especially the residual stress versus crack width curve, depends on the fiber factor, $F$, of the fibers added in the mixtures. The test curves indicate that SFRC with a higher content of steel fibers (see for example beams FL1.0 and SH0.8 with $V_{S F}=3 \%$ and $1.5 \%$, respectively, and $F=1.0$ and 0.8 , respectively) demonstrate higher post-cracking stress with regard to the corresponding SFRC mixtures with lower steel fiber content (see for example beams FL0.3 and SH0.3 with $V_{S F}=1 \%$ and $0.5 \%$, respectively and $F=0.3$, both of them).

It is also deduced that the fiber factor, $F$, is a more efficient parameter than the volume fraction, $V_{S F}$, for the evaluation of the steel fiber contribution on the residual stress since SFRC mixtures with the same fiber factor $F=0.3$ and different steel fiber content, such as beam FL0.3 with $V_{S F}=1 \%$ and beams SH0.3, SH0.3-s37 and SH0.3-s50 with $V_{S F}=0.5 \%$ exhibit more or less the same post-cracking stress (approximately 0.6 MPa), as shown in Figure 3a,b.

Furthermore, the comparison between the experimental and the analytical diagrams of Figure $3 a, b$ reveals that the stress versus crack width curves derived from the proposed smeared crack analysis that takes into account the tension softening phenomenon are in very good compliance with the test results.

\subsection{Proposed Model, Constitutive Relationships of the Materials and Nonlinear FE Analysis}

A nonlinear 3D FE analysis has been performed to predict the response of slender and deep SFRC beams with steel reinforcement subjected to reversal cyclic loading. This way, the efficacy and accuracy of the developed FE model are checked using experimental data of SFRC beams failing in flexure and in shear. The performed analysis adopts properly modified constitutive laws of the materials that consider the influence of the added steel fibers to the compressive and to the tensile behavior of SFRC with tension softening and residual stiffness effect.

The constitutive laws of SFRC under reversal compression and tension are based on test results and models that have been addressed by the authors in previous relative studies. Especially for the simulation of the tensional response of SFRC, a smeared crack analysis with tension softening is adopted. This model uses the fracture characteristics of the material taking into account stress versus crack width constitutive laws with post-cracking descending part (softened tensional behavior). The post-cracking response of SFRC under tension near the reinforcing bars is simulated by a residual stiffness approach that combines the interaction of steel fibers in the cracked concrete regions, the bond performance of steel reinforcing bars corresponding to the tension stiffening effect, the reinforcement characteristics and the fracture mechanics of SFRC. Furthermore, the performed FE analysis utilizes the concrete damaged plasticity (CDP) approach [68] to simulate the behavior of SFRC.

\subsubsection{SFRC under Reversal Compression}

It is known that steel fibers become more effective after cracking and, therefore, they mainly improve the post-peak compressive response of SFRC elements. The content, the geometrical and the bond properties of the added fibers are the main parameters that influence the enhanced post-cracking behavior of SFRC under compression [69-71]. The ultimate stress is slightly increased due to the presence of steel fibers since their progressive debonding failure improves the crack growth resistance of the material that undergoes after the compressive strength. Most of the proposed models of the literature that simulate the SFRC under compression are based on test results and proper regression analysis [72-76].

The proposed model for SFRC under reversal compression is illustrated in Figure 4. It can simulate the observed properties of the material behavior, such as the cracking and crushing of SFRC, the accumulation of damage (fracture), and the degradation of stiffness under cyclic loading. The SFRC constitutive law can be defined using multiple points on the compressive stress-strain $\left(\sigma_{c}-\varepsilon_{c}\right)$. A user-defined damage curve is implemented in the proposed $\mathrm{FE}$ analysis to account for the gradual SFRC stiffness degradation as the cracks spread. When the unloading takes place after the first 
crack formulation, the unloading branch stiffness is equivalent to the elastic stiffness, decreased by a factor, $d_{c}$, which considers the degradation due to damage. A substantial decrease in the stiffness is observed up to the full closure of the crack. The crack closure stage ends when the elastic displacement is restored. At this point, the elastic stiffness is also restored, and tension is performed.

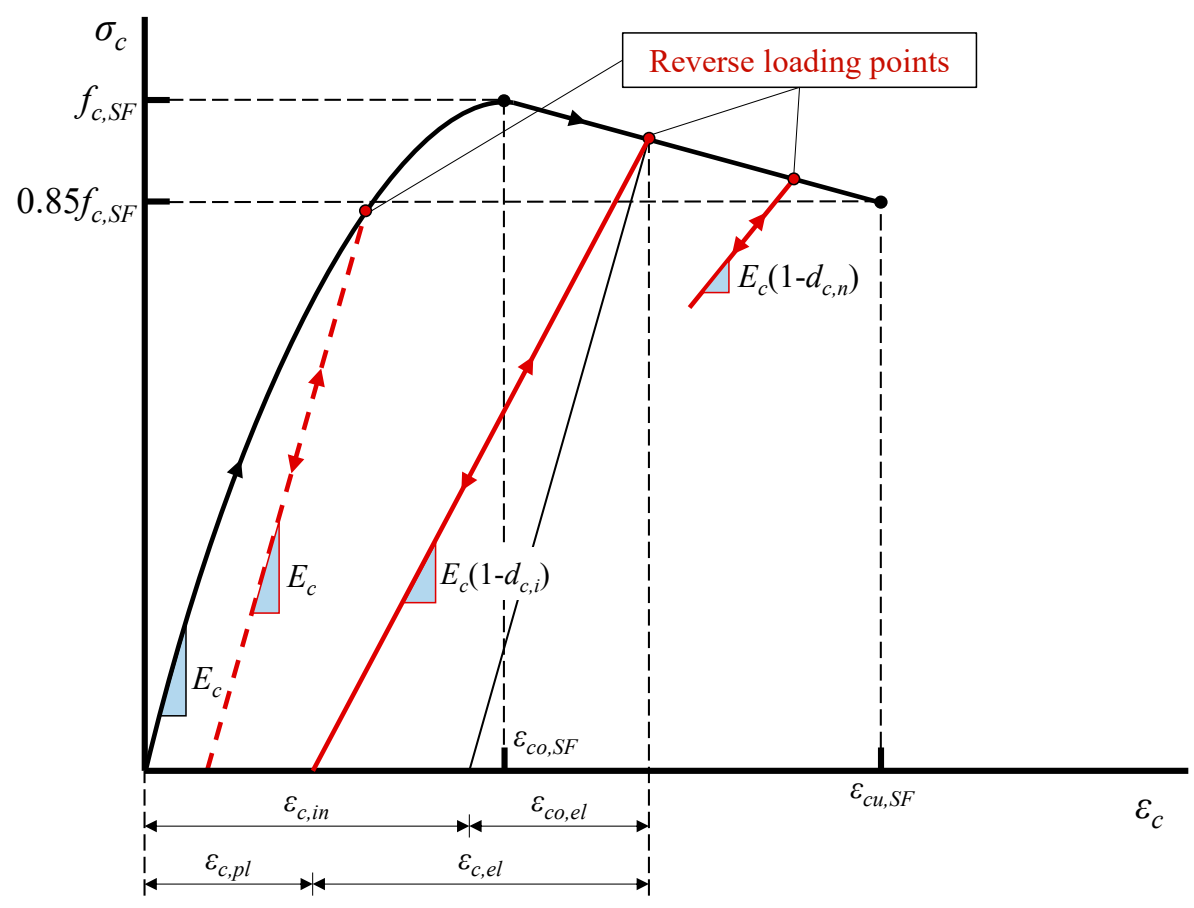

Figure 4. Model of SFRC under reversal compression.

The uniaxial compressive behavior of SFRC in relation to the CDP model can be formulated using stress versus plastic strain curves. The stress and the strain parameters of the proposed reversal compressive response shown in Figure 4 are calculated as follows:

$$
\begin{gathered}
\sigma_{c}=\left(1-d_{c}\right) E_{c}\left(\varepsilon_{c}-\varepsilon_{c, p l}\right), \\
\varepsilon_{c, p l}=\varepsilon_{c, i n}-\frac{d_{c}}{1-d_{c}} \varepsilon_{c o, e l}, \\
\varepsilon_{c, i n}=\varepsilon_{c}-\varepsilon_{c o, e l}, \\
\varepsilon_{c o, e l}=\sigma_{c} / E_{c,}
\end{gathered}
$$

where $E_{c}$ is the initial elastic modulus of SFRC under compression and $d_{\mathcal{c}}$ is the compressive plastic damage factor that takes values $0 \leq d_{c} \leq 1$ : 0 for the undamaged SFRC and 1 for the complete loss of the SFRC compressive strength, $f_{c, S F}$ :

$$
d_{c}=1-\sigma_{c} / f_{c, S F}
$$

The analytical formulation of the compressive stress-strain behavior of SFRC adopted in this study has been derived from test data of 125 stress versus strain curves and 257 strength values [77]. The ascending part of the compressive behavior until the ultimate strength of commonly used SFRC with $f_{c, S F} \leq 50 \mathrm{MPa}$ is expressed by (see also Figure 4):

$$
\sigma_{c}=f_{c, S F}\left[1-\left(1-\frac{\varepsilon_{\mathcal{C}}}{\varepsilon_{c o, S F}}\right)^{2}\right],
$$

where $\varepsilon_{c o, S F}$ is the strain corresponding to the maximum compressive stress, $f_{c, S F}$, of the SFRC. 
Concerning the post-peak compressive behavior, a linear descending part is considered from the ultimate strength, $f_{c, S F}$, until the value of $0.85 f_{c, S F}$ is obtained. The SFRC compressive strength, $f_{c, S F}$, the corresponding strain, $\varepsilon_{\mathcal{C O}, S F}$, and the strain, $\varepsilon_{\mathcal{C} u, S F}$, corresponding to the stress value $0.85 f_{\mathcal{C}, S F}$ are estimated by [77]:

$$
\begin{gathered}
f_{c, S F}=f_{c}(0.2315 F+1), \\
\varepsilon_{c o, S F}=\varepsilon_{c o}(0.95 F+1), \\
\varepsilon_{c u, S F}=\varepsilon_{c o, S F}(1.40 F+1),
\end{gathered}
$$

where $f_{c}$ is the compressive strength of plain concrete, $\varepsilon_{c o}$ is the corresponding strain that is usually equal to $0.002, F$ is the fiber factor $F=\beta V_{S F}\left(l_{S F} / d_{S F}\right)$, where $\beta$ is a bond factor (taken 0.50 for round, 0.75 for deformed and 1.0 for indented fibers), $V_{S F}$ is the volume fraction of the steel fibers and $l_{S F}$ and $d_{S F}$ are their length and diameter, respectively.

\subsubsection{SFRC under Reversal Tension}

The performance of concrete under tension can be substantially improved by the addition of steel fibers since SFRC exhibits increased tensile strength and mainly post-peak deformation capability showing pseudo-ductile behavior due to the gradual debonding failure of the fibers [78]. Various analytical stress versus strain expressions have been proposed to simulate the SFRC tensile behavior [79-81]. In this study, a smeared crack model for plain concrete with tension softening that has been addressed and experimentally verified by the authors $[82,83]$ is adopted. This model has properly been modified to simulate the favorable influence of steel fibers in SFRC under tension. Smeared crack approaches have also been used to evaluate the uncertainty of crack width in large-scale RC beams [84]. Furthermore, the uniaxial tensile response of SFRC in relation to the CDP model can be formulated using stress versus plastic strain curves. The parameters used in the proposed reversal tensile behavior shown in Figure 5 are calculated as follows:

$$
\begin{gathered}
\sigma_{t}=\left(1-d_{t}\right) E_{t, S F}\left(\varepsilon_{t}-\varepsilon_{t, p l}\right), \\
\varepsilon_{t, p l}=\varepsilon_{t, c r}-\frac{d_{t}}{1-d_{t}} \varepsilon_{t o, e l}, \\
\varepsilon_{t, c r}=\varepsilon_{t}-\varepsilon_{t o, e l}, \\
\varepsilon_{t o, e l}=\sigma_{t} / E_{t, S F},
\end{gathered}
$$

where $E_{t, S F}$ is the initial elastic modulus of SFRC under tension and $d_{t}$ is the tensile damage factor, which takes values $0 \leq d_{t} \leq 1$ : 0 for the undamaged SFRC and 1 for the complete loss of the SFRC tensile strength, $f_{t, S F}$ :

$$
d_{t}=1-\sigma_{t} / f_{t, S F}
$$

The analytical formulation of the proposed smeared crack approach for the post-cracking tensile behavior of SFRC utilizes stress versus crack width relationships. SFRC cracking takes place within a fracture process zone that is initiated at the tensile strength of SFRC, $f_{t, S F}$. The boundary of the strain-softening region and the SFRC characteristics define this zone, assuming that less damaged or even elastic parts coexist between the cracks of this fracture process zone. The total tensional strain, $\varepsilon_{t}$, is estimated as the sum of an elastic, $\varepsilon_{t o, e l}$, and a fracture component, $\varepsilon_{t, f r}$ (see also Figure 5):

$$
\begin{aligned}
& \varepsilon_{t}=\varepsilon_{t o, e l}+\varepsilon_{t, f r}, \\
& \varepsilon_{t, f r}=w_{t} / L_{f r, S F},
\end{aligned}
$$

where $\sigma_{t}$ is the tensile stress, $w_{t}$ is the crack width and $L_{f r}, S F$ is the fracture process zone length that can be taken equal to $3 l_{s f}[85]$. 


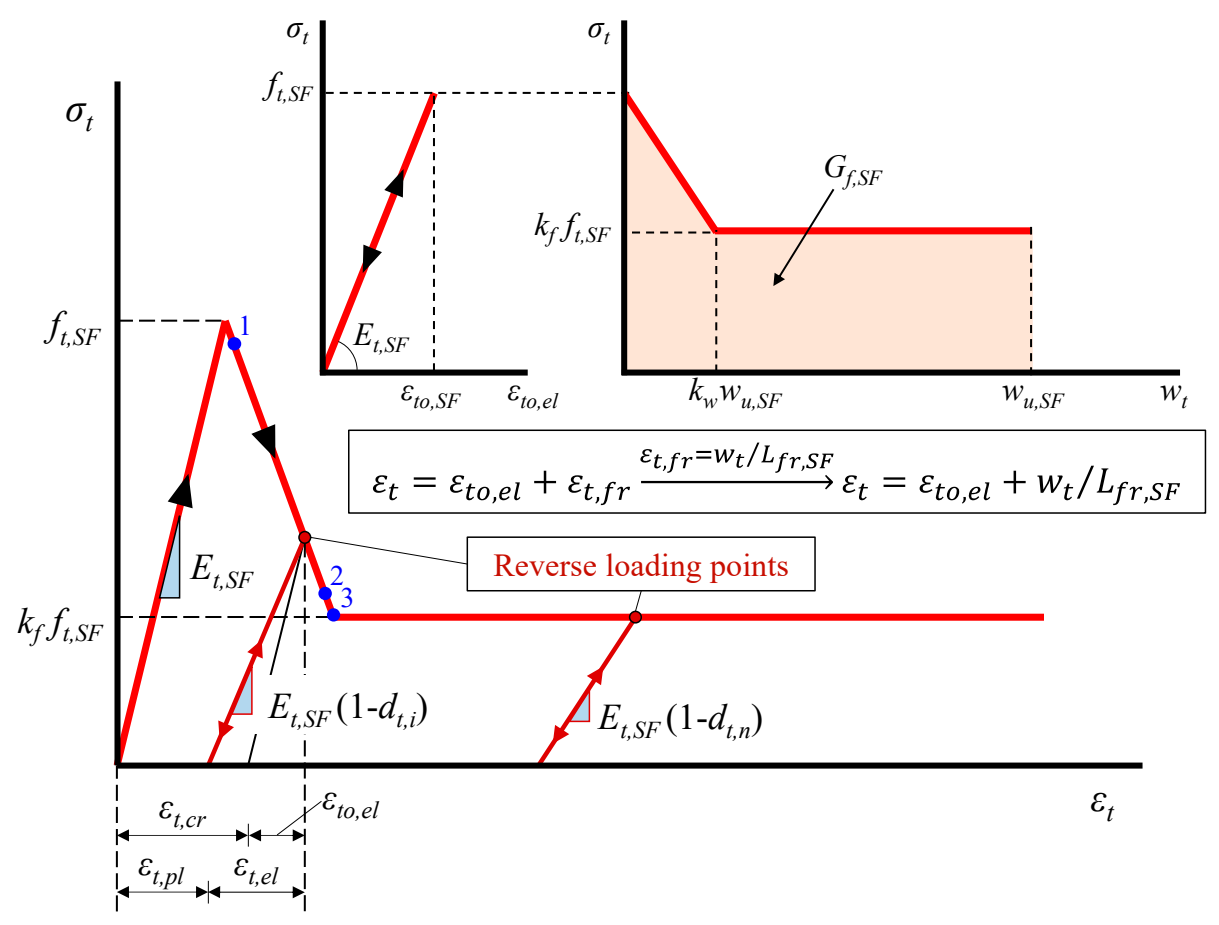

Figure 5. Model of SFRC under reversal tension.

The following equations describe the elastic component of the model (see also the linear $\sigma_{t}-\varepsilon_{t o, e l}$ diagram of Figure 5) [86]:

$$
\begin{gathered}
f_{t, S F}=\varepsilon_{t o, S F} E_{t, S F} \\
\varepsilon_{t o, S F}=0.167 n_{l, e l} V_{S F}\left(f_{S F} / E_{S F}-f_{t} / E_{t}\right)+f_{t} / E_{t}, \\
E_{t, S F}=\frac{3}{8}\left[E_{t}\left(1-V_{S F}\right)+E_{S F} V_{S F}\right]+\frac{5}{8}\left[\frac{E_{S F} E_{t}}{E_{S F}\left(1-V_{S F}\right)+E_{t} V_{S F}}\right],
\end{gathered}
$$

where $E_{t, S F}$ is the modulus of elasticity under tension of SFRC, $f_{t}$ and $E_{t}$ are the ultimate tensile strength and the elastic modulus under tension of the plain concrete, respectively, $f_{S F}$ and $E_{S F}$ are the tensile strength and the elastic modulus of the steel fiber, respectively, and $n_{l, e l}$ is the ratio of the average elastic stress to the strength of the steel fiber that is usually equal to 0.5 [86].

The properties of the SFRC softening and fracture response define the parameters of the fracture components of the proposed smeared crack approach $[87,88]$. The fracture energy, $G_{f, S F}$, is the energy required for the cracking formation within the fracture process zone and for the full opening of one single crack [89]:

$$
G_{f, S F}=\int_{f_{t, S F}}^{0} \sigma_{t} d w_{t} \stackrel{w_{t}=L_{f r, S F} \varepsilon_{t, f r}}{\rightarrow} G_{f, S F}=L_{f r, S F} \int_{f_{t, S F}}^{0} \sigma_{t} d \varepsilon_{t, f r},
$$

The post-peak behavior shown in the $\sigma_{t}-w_{t}$ curve of Figure 5 is defined by a linear descending part until the point of the maximum post-cracking tensional stress, $k_{f} f_{t, S F}$, and the corresponding crack width, $k_{w} w_{u, S F}$. After this point, the stress is assumed to have the following constant value until the ultimate crack width, $w_{u, S F}: \sigma_{t}=k_{t} f_{t, S F}\left(w_{t}>k_{w} w_{u, S F}\right)$. The fracture energy is the area under the curve of SFRC stress versus crack width (see also the bilinear $\sigma_{t}-w_{t}$ diagram of Figure 5):

$$
G_{f, S F}=f_{t, S F} w_{u, S F}\left(k_{f}+0.5 k_{w}-0.5 k_{f} k_{w}\right),
$$


where the values of the coefficients $k_{f}$ and $k_{w}$ depend on the SFRC characteristics as [85]:

$$
\begin{gathered}
k_{f}=\frac{0.405 n_{l} \sigma_{f u} V_{S F}}{\varepsilon_{t o, S F} E_{t, S F}}, \\
k_{w}=\frac{(3 \div 8) L_{f r, S F} \varepsilon_{t o, S F}}{w_{u, S F}}
\end{gathered}
$$

where $\sigma_{f u}$ is the maximum stress of the fiber when a uniform bond stress, $\tau_{u}$, is assumed at the interface between the steel fiber and the concrete:

$$
\begin{gathered}
\sigma_{f u}=\left\{\begin{array}{cc}
2 \tau_{u} l_{S F} / d_{S F} & l_{S F} \leq l_{c r} \\
f_{S F} & l_{S F}>l_{c r}
\end{array}\right\}, \\
n_{l}=\left\{\begin{array}{cc}
0.50 & l_{S F} \leq l_{c r} \\
1-\frac{l_{S F}}{2 l_{c r}} & l_{S F}>l_{c r}
\end{array}\right\},
\end{gathered}
$$

where $l_{c r}$ is the length of the fiber in which the ultimate fiber stress is developed:

$$
l_{c r}=0.5 f_{S F} d_{S F} / \tau_{u}
$$

The fracture energy, $G_{f, S F}$, can been estimated by tension tests as a function of the known steel fiber factor, $F$, and the value of the fracture energy of the plain concrete, $G_{f}[85]$ :

$$
G_{f, S F}=G_{f}(104 F+1),
$$

where the fracture energy of the plain concrete, $G_{f}$, can be calculated using linear relation from the tensile strength of concrete, $f_{t}$, to zero at the maximum crack width, $w_{u}$ :

$$
\begin{gathered}
G_{f}=0.5 f_{t} w_{u} \\
w_{u}=\varepsilon_{t u, f r} L_{f r} \stackrel{\varepsilon_{t u, f r}=a_{f r} \varepsilon_{t o}}{\rightarrow} w_{u}=a_{f r} \varepsilon_{t o} L_{f r} \stackrel{\varepsilon_{t o}=f_{t} / E_{t}}{\rightarrow} w_{u}=a_{f r} L_{f r} \frac{f_{t}}{E_{t}}
\end{gathered}
$$

where $a_{f r}$ is a coefficient that takes values from 5 to 8 for maximum aggregate size $d_{g}=32$ to $8 \mathrm{~mm}$, respectively [82], and $L_{f r}$ is the plain concrete fracture process that can be taken as $3 d_{g}$ [90]). This way, Equation (21) can be written as:

$$
\begin{gathered}
f_{t, S F} w_{u, S F}\left(k_{f}+0.5 k_{w}-0.5 k_{f} k_{w}\right)=0.5 f_{t} a_{f r} L_{f r} \frac{f_{t}}{E_{t}}(104 F+1) \stackrel{L_{f r}=3 d_{g}}{\rightarrow}, \\
w_{u, S F}=\frac{1.5 f_{t}^{2} a_{f r} d_{g}(104 F+1)}{f_{t, S F} E_{t}\left(k_{f}+0.5 k_{w}-0.5 k_{f} k_{w}\right)}
\end{gathered}
$$

The stress at each stage can be calculated as:

$$
\sigma_{t}=\left\{\begin{array}{cc}
\varepsilon_{t} E_{t, S F} & \text { if } 0<\varepsilon_{t} \leq \varepsilon_{t o, S F} \\
f_{t, S F}\left(1-\frac{1-k_{f}}{k_{w} w_{u, S F}} w_{t}\right) & \text { if } 0<w_{t} \leq k_{w} w_{u, S F} \\
k_{f} f_{t, S F} & \text { if } k_{w} w_{u, S F}<w_{t} \leq w_{u, S F}
\end{array}\right\},
$$

Furthermore, the following CDP-material-associated parameters define the inelastic behavior of SFRC [91] and their values used herein are presented in Table 3: 
Table 3. Concrete damaged plasticity (CDP) model input parameters.

\begin{tabular}{cc}
\hline Parameter & Value \\
\hline$\psi$ & $40^{\circ}$ \\
$K_{c}$ & $2 / 3$ \\
$\sigma_{b 0} / \sigma_{c 0}$ & 1.16 \\
$\epsilon$ & 0.10 \\
$\mu$ & 0.0001 \\
\hline
\end{tabular}

Where $\psi$ is the dilatation angle affecting the plastic deformation, $\in$ is the flow potential eccentricity that defines the rate of the plastic potential hyperbolic to its asymptote, $\sigma_{b o} / \sigma_{c o}$ is the ratio of the strength in the biaxial state to the strength in the uniaxial state, $K_{c}$ is the ratio of the tensile to the compressive meridian and $\mu$ is the viscosity parameter.

\subsubsection{Modeling of Steel Reinforcement}

The cyclic response of the steel reinforcing bars and stirrups is derived by a superposition of several elastic and perfectly plastic models in parallel. This takes account of a nonlinear kinematic positive strain-hardening since plastic behavior is defined by the values of the yield strength and the corresponding plastic strain $\left(f_{y}, \varepsilon_{y}\right)$, the ultimate strength and the corresponding strain $\left(f_{u}, \varepsilon_{u}\right)$ and is characterized by permanent deformations. The values of the steel modulus of elasticity, $E_{s}$, and Poisson's ratio are also used in the FE analysis according to the test data of the steel reinforcement.

\subsubsection{Element Types}

SFRC was simulated by using 8-node 3-dimensional solid elements with reduced integration (C3D8R) to avoid the effect of shear locking. The 3-dimensional 2-node truss elements (T3D2) were selected for the simulation of steel reinforcement (longitudinal and stirrups). Every element's node has three degrees of freedom with $\mathrm{x}, \mathrm{y}$, and $\mathrm{z}$ (global coordinate system) translation, as depicted in Figure 6 . The bond between reinforcement and concrete is modeled using the embedded process, and precisely the Abaqus feature "truss in solid" [85].

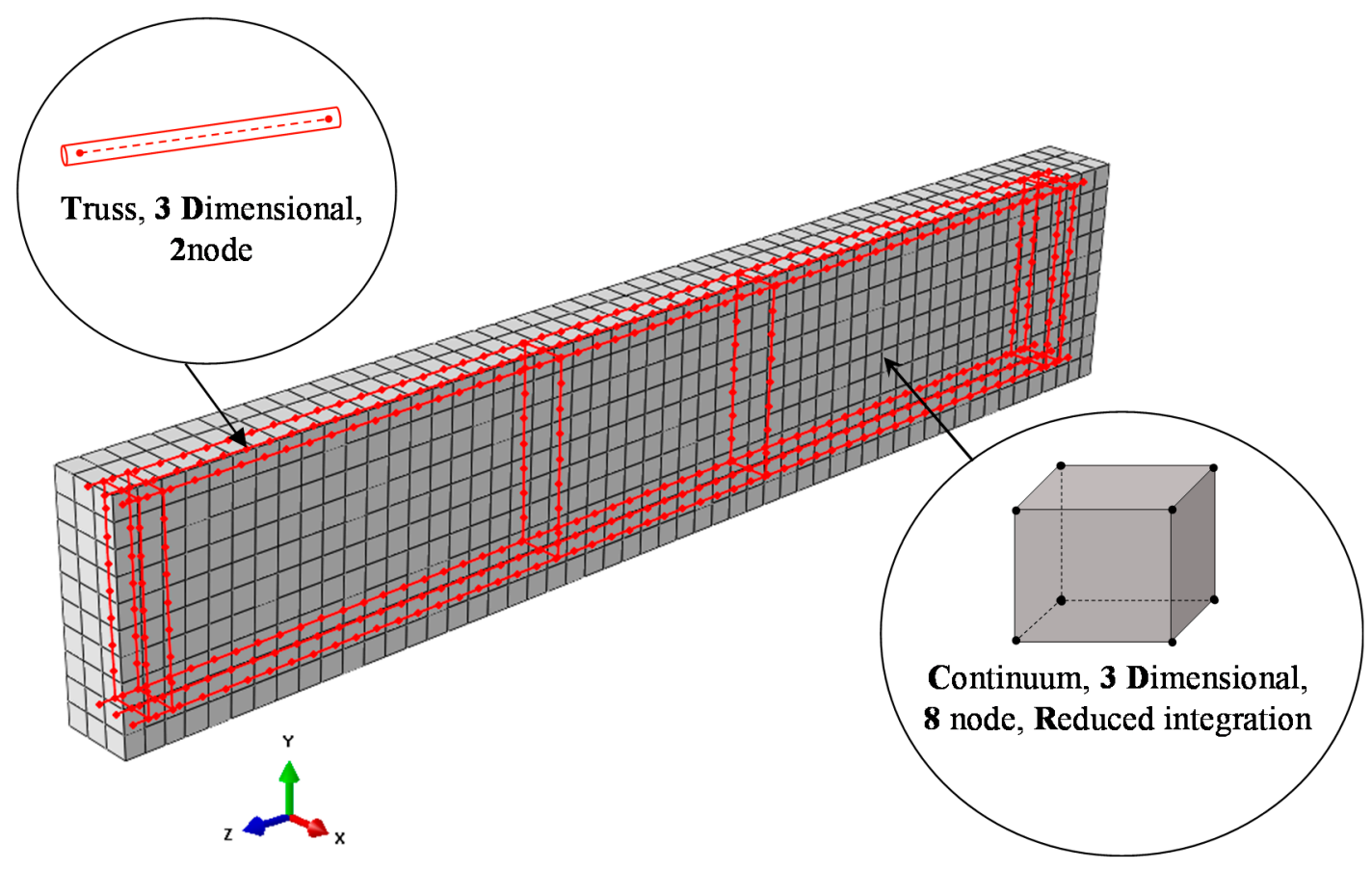

Figure 6. Finite element (FE) mesh of the SFRC and the steel reinforcement of the beam. 


\subsubsection{Boundary Conditions}

The simulated beam's boundary conditions were adopted according to the experimental setup shown in Figure 7. The supports were positioned at a particular distance from each edge, while the edges remained free. At the left side, a line of nodes was constrained in the Ux, Uy, Uz directions, while at the right side only the Uy direction was constrained.

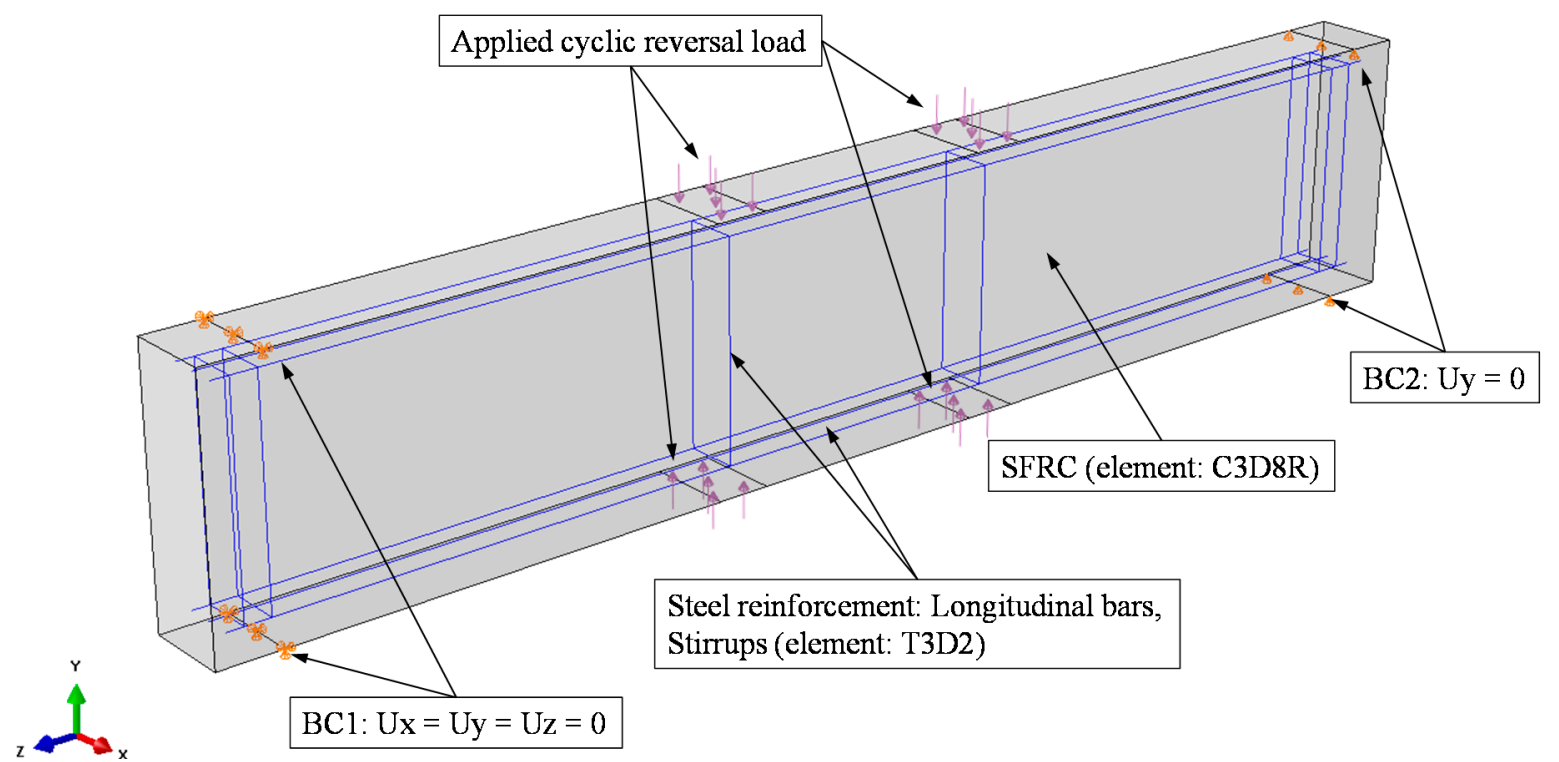

Figure 7. Boundary conditions and loading of the FE simulation of the beam.

\subsubsection{Loading, Mesh and Convergence}

The load was applied to the beam specimens in a quasi-static manner as a reverse cyclic loading, which implies that each cycle consisted of loading in both directions, as shown in Figure 7. Analysis up to load failure capacity of the tested SFRC beams was beyond the scope of this study. The slender beams were subjected to displacement control while the deep beams to load control cyclic histories. Furthermore, the load was applied constantly and smoothly to achieve a quasi-static solution and prevent any essential acceleration alteration through each iteration, which further ensures that the stress and displacement changes remain smooth.

Mesh size was selected based on the assumption that the distribution of SFRC cracking typically includes spatial scales between two to three dominant aggregate sizes of the concrete mixture [90]. The maximum aggregate size for the slender and the deep beams was 16 and $9.5 \mathrm{~mm}$, respectively. Mesh sizes of 40 and $30 \mathrm{~mm}$ have been applied to all types of elements (truss and solid).

\subsubsection{FE Simulation of the Tested Beams and Material Input}

The simulations of the examined SFRC beam specimens were developed according to the geometrical and mechanical properties of the tested beams and the boundary conditions of the experimental setup. The aspects of the developed FE modeling are described in Sections 2.2.1-2.2.7 of this paper. Furthermore, the main characteristics of the materials for each specimen are presented in Tables 1 and 2. Supplementary input parameters are presented in Table 4 . Stress, $\sigma$, crack width, $w$, and strain, $\varepsilon$, values at points 1,2 and 3 , and the corresponding plastic damage factors, $d_{t}$, of Table 4 are defined in the tensional behavioral model of the SFRC shown in Figure 5. 
Table 4. Supplementary input variables for the simulation of the tested SFRC beams.

\begin{tabular}{cccccccccccccc}
\hline $\begin{array}{c}\text { Beam } \\
\text { Name }\end{array}$ & $\boldsymbol{v}$ & $\begin{array}{c}\sigma_{t \mathbf{1}} \\
(\mathbf{M P a})\end{array}$ & $\begin{array}{c}\boldsymbol{w}_{t \mathbf{1}} \\
(\mathbf{m m})\end{array}$ & $\begin{array}{c}\varepsilon_{t \mathbf{1}} \\
(\mathbf{m m} / \mathbf{m})\end{array}$ & $\begin{array}{c}\sigma_{t 2} \\
(\mathbf{M P a})\end{array}$ & $\begin{array}{c}\boldsymbol{w}_{t \mathbf{2}} \\
(\mathbf{m m})\end{array}$ & $\begin{array}{c}\varepsilon_{t 2} \\
(\mathbf{m m} / \mathbf{m})\end{array}$ & $\begin{array}{c}\sigma_{t 3} \\
(\mathbf{M P a})\end{array}$ & $\begin{array}{c}\boldsymbol{w}_{t 3} \\
(\mathbf{m m})\end{array}$ & $\begin{array}{c}\varepsilon_{t 3} \\
(\mathbf{m m} / \mathbf{m})\end{array}$ & $\boldsymbol{d}_{t \mathbf{1}}$ & $\boldsymbol{d}_{\boldsymbol{t} \mathbf{2}}$ & $\boldsymbol{d}_{\boldsymbol{t} \mathbf{3}}$ \\
\hline FL0.3 & 0.212 & 2.56 & 0.012 & 0.09 & 1.07 & 0.034 & 0.26 & 0.62 & 0.045 & 0.34 & 0.225 & 0.676 & 0.811 \\
FL1.0 & 0.237 & 3.69 & 0.013 & 0.10 & 2.29 & 0.041 & 0.31 & 1.87 & 0.053 & 0.40 & 0.159 & 0.478 & 0.573 \\
\hline SH0.3-s37 & 0.210 & 1.87 & 0.011 & 0.06 & 0.84 & 0.032 & 0.18 & 0.53 & 0.045 & 0.25 & 0.219 & 0.656 & 0.787 \\
SH0.3-s50 & 0.210 & 1.87 & 0.011 & 0.06 & 0.84 & 0.032 & 0.18 & 0.53 & 0.045 & 0.25 & 0.219 & 0.656 & 0.787 \\
\hline SH0.3 & 0.210 & 1.87 & 0.011 & 0.06 & 0.84 & 0.032 & 0.18 & 0.53 & 0.043 & 0.24 & 0.216 & 0.648 & 0.778 \\
SH0.4 & 0.216 & 1.98 & 0.011 & 0.06 & 1.07 & 0.032 & 0.18 & 0.80 & 0.041 & 0.23 & 0.187 & 0.561 & 0.673 \\
SH0.6 & 0.215 & 2.24 & 0.011 & 0.06 & 1.33 & 0.034 & 0.19 & 1.06 & 0.045 & 0.25 & 0.168 & 0.504 & 0.605 \\
SH0.8 & 0.231 & 2.46 & 0.011 & 0.06 & 1.79 & 0.032 & 0.18 & 1.59 & 0.043 & 0.24 & 0.119 & 0.357 & 0.428 \\
\hline
\end{tabular}




\section{Results and Discussion}

\subsection{Verification of the Model}

The numerical results yielded from the developed nonlinear FE simulations are compared with the experimental data using load versus hysteretic deformation curves. Figures 8 and 9 clearly demonstrate the analytical and the test curves of the slender beams FL0.3 and FL1.0 with steel fiber factor $F=0.3$ $\left(V_{S F}=1 \%\right)$ and $F=1.0\left(V_{S F}=3 \%\right)$, respectively, for each loading cycle (see the three diagrams of the 1st, 2nd and 3rd cycle in Figures 8 and 9).

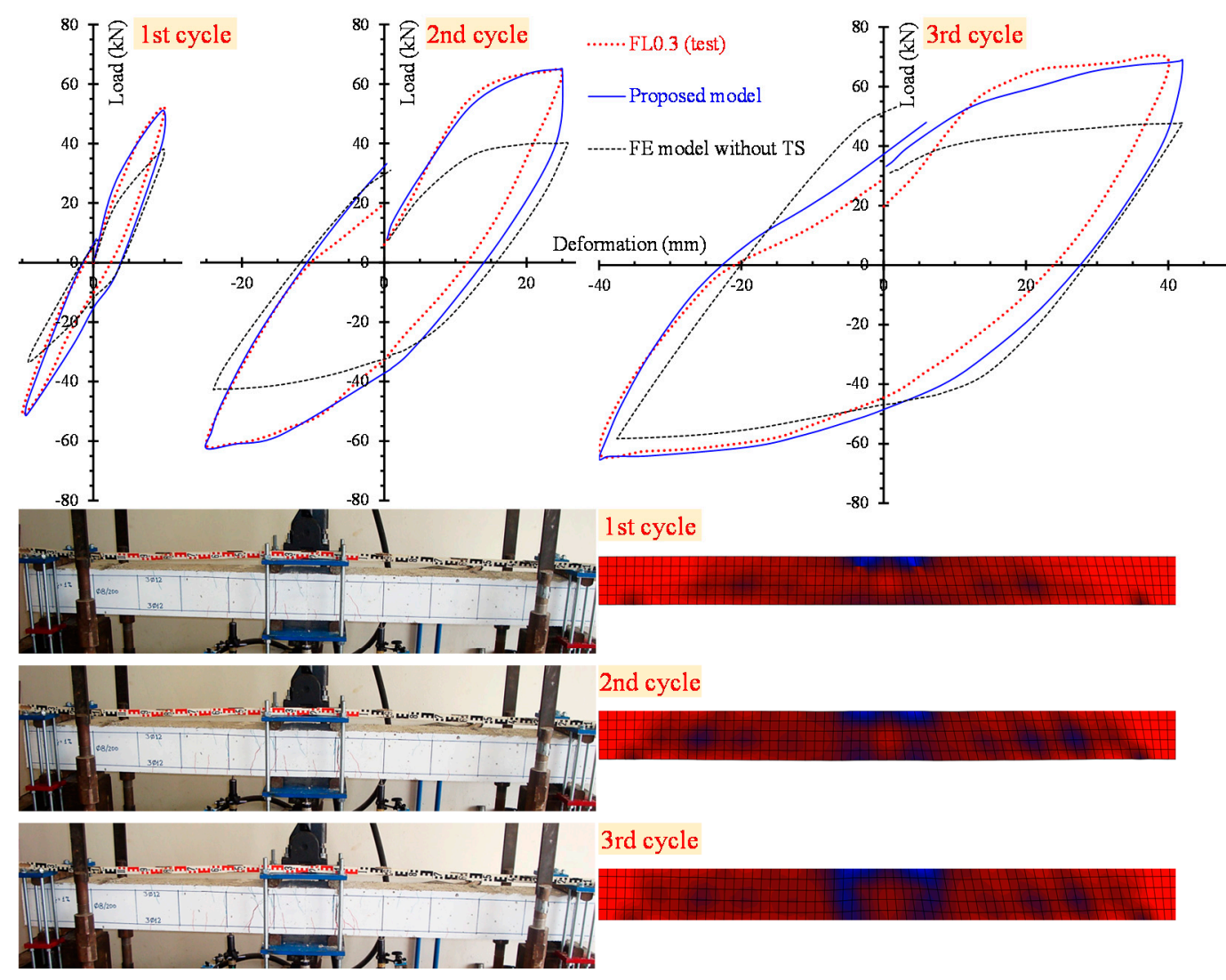

Figure 8. Comparisons between the analytical and experimental results of slender beam FL0.3 in load versus deformation curves and cracking patterns for the 1st, 2nd and 3rd loading cycle.

In order to comprehend the effect of the tension softening and the residual stiffness on the flexural hysteretic response of the tested SFRC beams, two analytical curves are compared with the test curve in Figures 8 and 9. The first curve (continuous blue line) has been derived from the proposed nonlinear FE smeared crack analysis with tension softening and residual stiffness approach and the second curve (black thin dotted line) from the FE analysis without taking into account this effect (denoted as "FE model without TS" in Figures 8 and 9).

Figures 8 and 9 also present the cracking patterns of the flexural beams FL0.3 and FL1.0, respectively, at each loading cycle obtained from the tests and compared to the corresponding cracking pattern at the same loading level derived from the proposed analysis using stress distribution data. Experimental and numerical crack propagation due to flexure at the end of each hysteretic loading cycle are in good compliance.

The ability of the proposed model to calculate accurately the entire hysteretic load versus the deformation behavior of SFRC beams with different failure modes and various steel fiber volumetric fractions is examined in Figures 10-12. In these Figures, the analytical and the experimental hysteretic response and cracking patterns at the failure of the shear-critical beams are compared. Each load versus 
deformation diagram includes an experimental and two numerical curves yielded from the proposed FE analysis with tension softening and a residual stiffness effect (continuous blue line) and form the FE analysis without taking into account this effect (black thin dotted line). Figure 10 presents the diagrams of shear-critical beams without stirrups SH0.3 and SH0.4, and Figure 11 shows the diagrams of shear-critical beams SH0.6 and SH0.8, also without stirrups. Figure 12 presents the diagrams of shear-critical beams with stirrups SH0.3-s37 and SH0.3-s50.

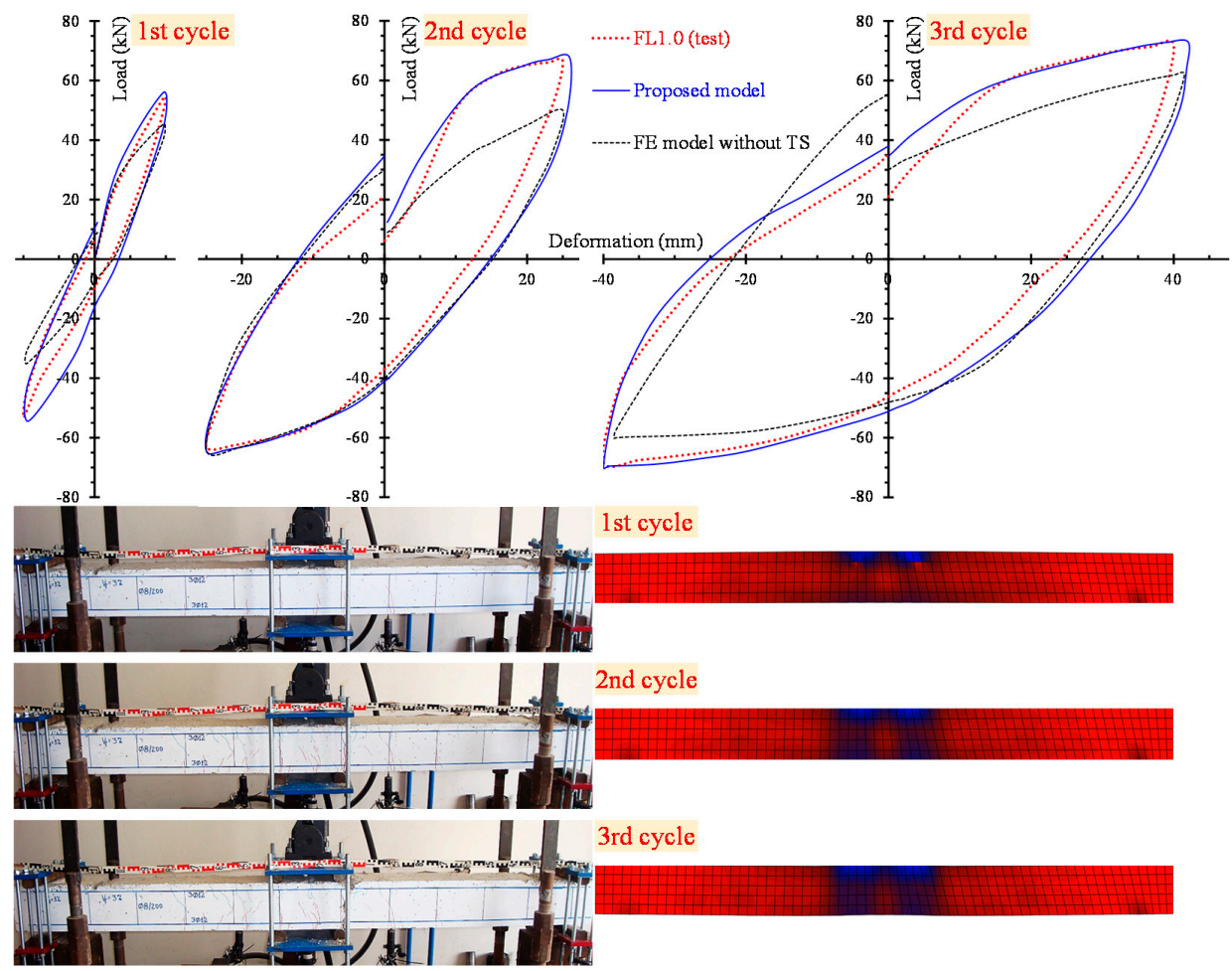

Figure 9. Comparisons between analytical and experimental results of slender beam FL1.0 in load versus deformation curves and cracking patterns for the 1st, 2nd and 3rd loading cycle.

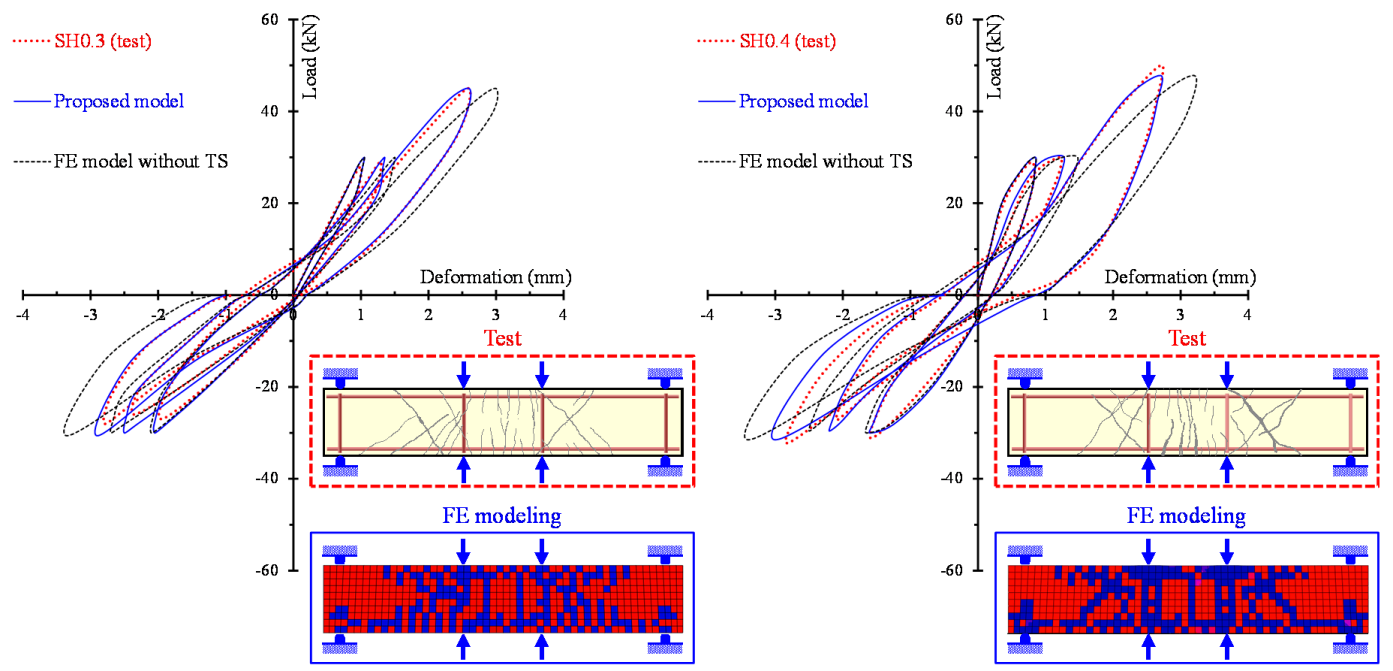

Figure 10. Comparisons between the analytical and experimental hysteretic response and cracking patterns of shear-critical beams without stirrups SH0.3 and SH0.4. 


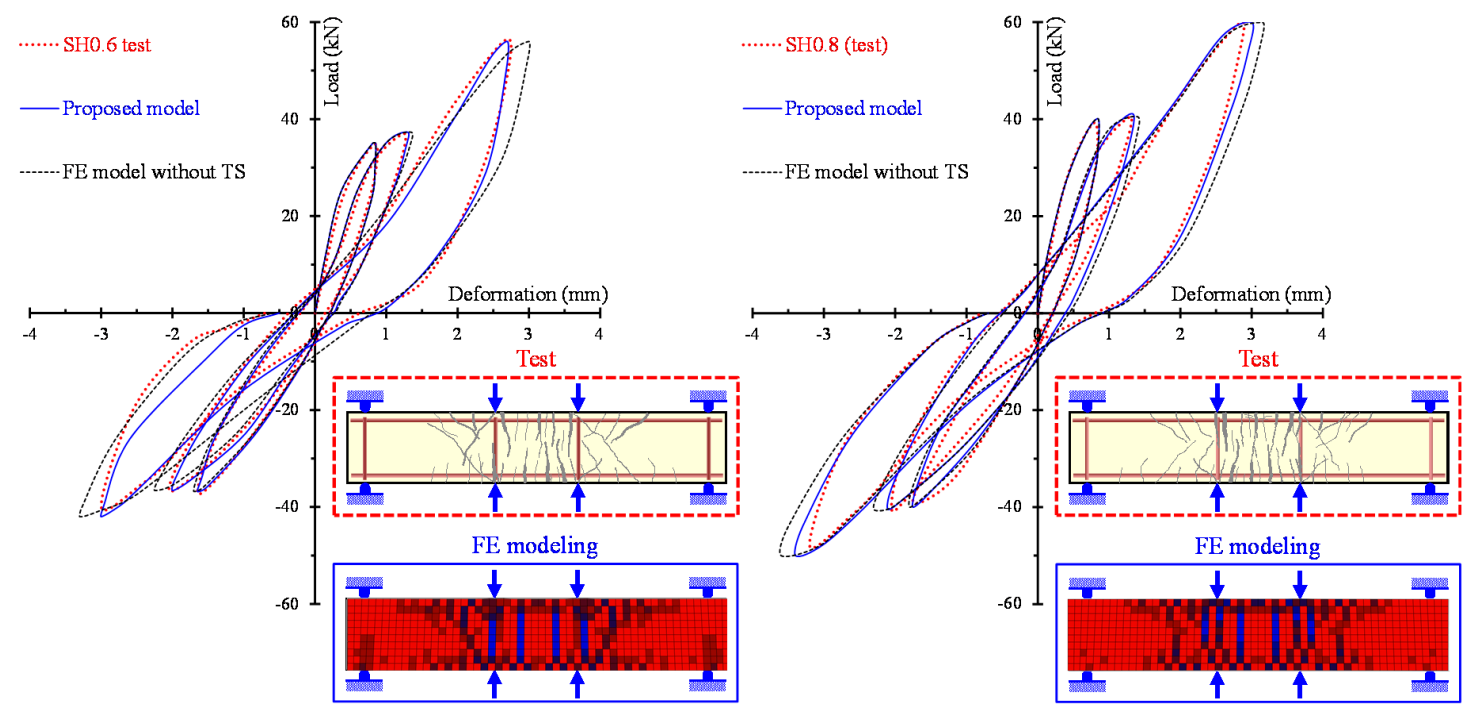

Figure 11. Comparisons between the analytical and experimental hysteretic response and cracking patterns of shear-critical beams without stirrups SH0.6 and SH0.8.
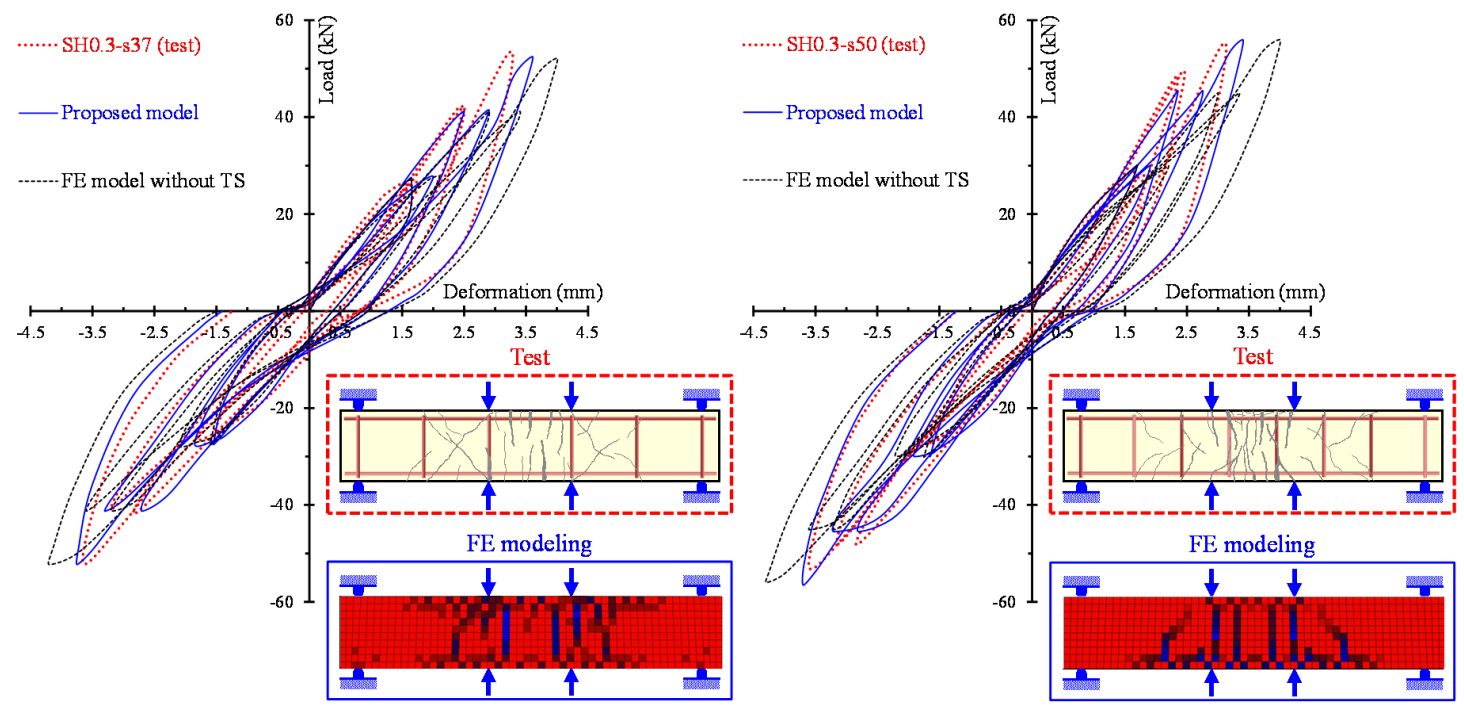

Figure 12. Comparisons between the analytical and experimental hysteretic response and cracking patterns of shear-critical beams with stirrups SH0.3-s37 and SH0.3-s50.

The comparisons of the hysteretic response obtained from the tests and derived from the proposed model, as illustrated in Figures 8-12, indicate that in most beams the predictions of the developed FE analysis that takes into account the smeared crack model with tension softening and residual stiffness effect are in closer agreement with the experimental data than the predictions without this effect. It is noted that numerical curves derived from the proposed model fit well to the test results in both types of beams that failed in flexure (specimens of group "FL") and in shear (specimens of groups "SH-s" and "SH"). Furthermore, the formation of cracks during the performed cyclic tests and the corresponding cracking patterns derived from the FE model exhibit many similarities.

\subsection{Analysis of the Hysteric Behavior and Accuracy of the Proposed Model}

The load, $P$, versus displacement, $\delta$, curves of the structural members under cyclic reversal loading are the basis of their hysteretic performance. Based on the test results as well as the FE analysis, the $P-\delta$ hysteretic curves for the SFRC beams have been created. 


\subsubsection{Simplification of the hysteretic Loop}

The hysteretic loop (or else full loading cycle) can be interpreted either by the actual path of the loop's curve, or, by parameters that define its general form. One of the essential properties of the hysteretic loop is its inclination. A complete loop comprises a loading and an unloading curve. After the first crack formation on the member, the slope of the loading curve decreases with the increase in displacement, indicating that the members' stiffness has decreased during each repeated loading cycle. Like the loading curve, the inclination of the unloading curve also declines as the number of cycles increases, and the members' unloading stiffness gradually degrades.

When the loading of the members starts, the member's stiffness is equal to the initial elastic deformation stiffness, $K_{i n}$, as shown in Figure 13a, this is also declared to be the maximum stiffness of the element. As the loading cycle proceeds, the loop inclination depends on the stiffness of the member, which can be estimated by the tangent stiffness, $K_{\tan }$, at any point throughout the loading phase (Figure 13b). The value of tangent stiffness varies throughout the cycle of loading, but its average value over the entire loop can be approximated by the cyclic stiffness, $K_{c y c l i c}$. The average value of tangent stiffness, $K_{t a n}$, for a half loading cycle can be approximated by the secant stiffness, $K_{s e c}$. When the loop is symmetrical the average values of $K_{s e c}{ }^{(+)}$and $K_{s e c}{ }^{(-)}$equal to the value of cyclic stiffness, $K_{\text {cyclic }}$. Referring to Figure 13a,b, in the linear elastic load range, $K_{i n}=K_{s e c}=K_{t a n}$. The use of $K_{s e c}$ is preferred rather than $K_{\tan }$ in the processing of test data because it is an order-of-magnitude less influenced by random errors. Nevertheless, $K_{\text {tan }}$ is preferred in numerical procedures that require the assembly of an incremental stiffness matrix. In this study $K_{\text {sec }}, K_{t a n}$ and $K_{c y c l i c}$ are calculated and compared for each cycle.

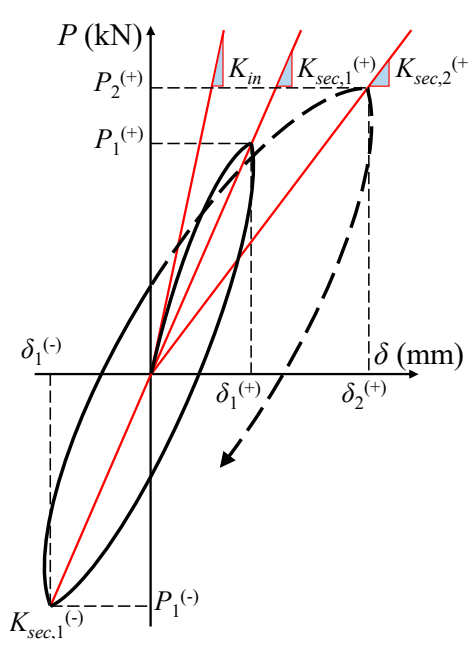

(a)

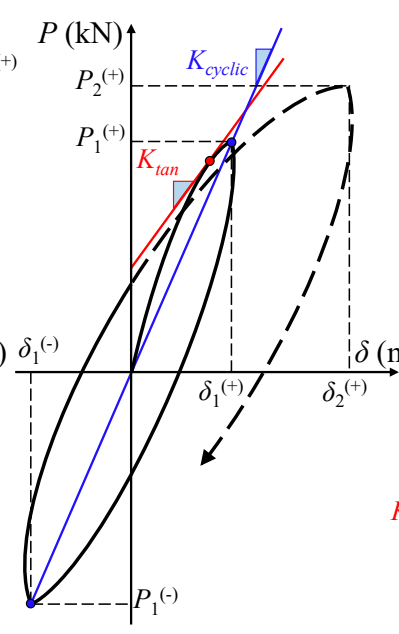

(b)

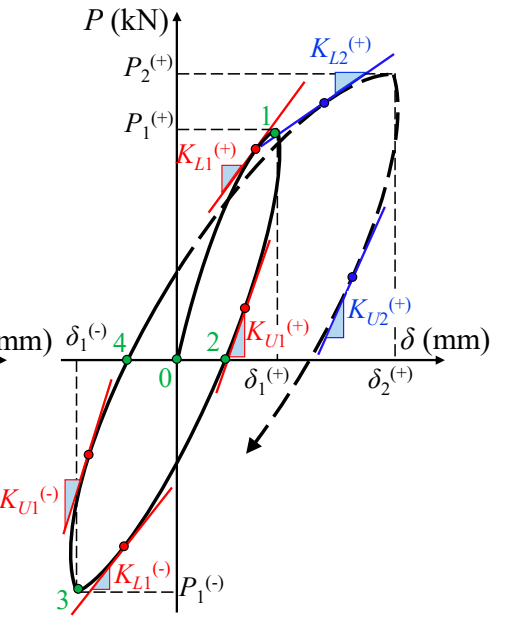

(c)

Figure 13. Definitions and variables of the hysteretic loop-loading cycle: (a) initial elastic deformation stiffness and secant stiffness; (b) tangent and cyclic stiffness; (c) loading and unloading stiffness during cyclic reversal imposed load.

\subsubsection{Degradation Analysis of Strength and Stiffness}

Stiffness is an important assessment index to evaluate the cyclic response of an SFRC member. Thus, stiffness at different points has been calculated and then statistically analyzed to evaluate the member's performance and the effectiveness of the proposed model. Tangent stiffness, $K_{\tan }$, has been calculated at multiple points in each loading cycle, according to Figure 13b. As shown in Figure 13c, the loading starts from point 0 to the unloading point 1 , and then reverse loading starts at point 2. During this process, along the path 0-1-2 the tangent stiffness of the member is changed from initial stiffness, $K_{i n}$, to tangent stiffness, $K_{L 1}{ }^{(+)}$, as the member's behavior changes from elastic to post-cracking, and then again after reaching the maximum loading point 1 of unloading starts and the 
tangent stiffness changes again from $K_{L 1}{ }^{(+)}$to $K_{U 1}{ }^{(+)}$. A half cycle is completed from point 0 to point 2 , the reverse loading starts from point 2 and increases until the reach of maximum point 3 , at which point, unloading starts again to the reverse unloading point 4 . During this reverse loading process, stiffness changes again from $K_{L 1}{ }^{(-)}$to $K_{U 1}{ }^{(-)}$. This process continuous in every next cycle until the end of the experimental testing.

\subsubsection{Accuracy of the Model}

In order to establish the validity and check the accuracy of the proposed nonlinear FE analysis, Tables 5-8 summarize the differences between the numerical calculations and the experimental results in terms of "calculation errors". The discrepancy of the load, the deformation and the stiffness (tangent, secant and cyclic) between the predictions and the tests along the entire hysteretic diagrams of each beam have been calculated in order to evaluate the accuracy of the examined models. The following know expression is used to calculate the discrepancy as a percentage error:

$$
\text { Error of VARiable }(\%)=\left|\frac{V A R_{\text {model }}-V A R_{\text {exp }}}{V_{\text {exp }}}\right| \times 100,
$$

where $V A R_{\text {model }}$ and $V A R_{\text {exp }}$ are the values of the examined variable derived from the numerical models (A: using the proposed model or B: using the FE model without tension softening and residual stiffness effect) and the experiments, respectively.

Table 5. Error calculation in the prediction of load, $P$ (slender beams), or deformation, $\delta$ (deep beams).

\begin{tabular}{|c|c|c|c|c|c|c|c|c|c|}
\hline \multirow{2}{*}{ Beam Name } & \multicolumn{6}{|c|}{ MAE at Each Cycle } & \multirow{2}{*}{$\begin{array}{c}\text { Overall } \\
\text { MAE }\end{array}$} & \multirow{2}{*}{ SE } & \multirow{2}{*}{ CV } \\
\hline & & Cycle 1 & Cycle 2 & Cycle 3 & Cycle 4 & Cycle 5 & & & \\
\hline \multirow{2}{*}{ FL0.3 } & A & $1.6 \%$ & $1.8 \%$ & $1.7 \%$ & - & - & $1.7 \%$ & $0.4 \%$ & $26 \%$ \\
\hline & B & $30.3 \%$ & $33.8 \%$ & $19.2 \%$ & - & - & $27.8 \%$ & $4.3 \%$ & $16 \%$ \\
\hline \multirow{2}{*}{ FL1.0 } & A & $2.6 \%$ & $1.9 \%$ & $2.2 \%$ & - & - & $2.2 \%$ & $0.3 \%$ & $12 \%$ \\
\hline & $\mathrm{B}$ & $25.4 \%$ & $13.2 \%$ & $12.7 \%$ & - & - & $17.1 \%$ & $4.6 \%$ & $27 \%$ \\
\hline \multirow{2}{*}{ SH0.3-s37 } & $\mathrm{A}$ & $1.6 \%$ & $9.5 \%$ & $3.9 \%$ & $7.7 \%$ & $6.8 \%$ & $5.9 \%$ & $1.7 \%$ & $29 \%$ \\
\hline & $\mathrm{B}$ & $3.2 \%$ & $4.2 \%$ & $17.6 \%$ & $25.7 \%$ & $19.1 \%$ & $13.9 \%$ & $3.7 \%$ & $26 \%$ \\
\hline \multirow{2}{*}{ SH0.3-s50 } & A & $0.1 \%$ & $5.6 \%$ & $1.1 \%$ & $8.1 \%$ & $6.2 \%$ & $4.2 \%$ & $1.5 \%$ & $36 \%$ \\
\hline & $\mathrm{B}$ & $3.1 \%$ & $22.2 \%$ & $22.4 \%$ & $26.9 \%$ & $24.2 \%$ & $19.8 \%$ & $3.7 \%$ & $19 \%$ \\
\hline \multirow{2}{*}{ SH0.3 } & A & $5.1 \%$ & $5.1 \%$ & $1.8 \%$ & - & - & $4.0 \%$ & $0.9 \%$ & $23 \%$ \\
\hline & B & $6.3 \%$ & $15.1 \%$ & $17.5 \%$ & - & - & $13.0 \%$ & $2.2 \%$ & $17 \%$ \\
\hline \multirow{2}{*}{ SH0.4 } & A & $3.9 \%$ & $3.6 \%$ & $2.6 \%$ & - & - & $3.4 \%$ & $1.0 \%$ & $27 \%$ \\
\hline & B & $4.7 \%$ & $18.9 \%$ & $18.9 \%$ & - & - & $14.2 \%$ & $3.0 \%$ & $20 \%$ \\
\hline \multirow{2}{*}{ SH0.6 } & A & $0.1 \%$ & $3.2 \%$ & $0.0 \%$ & - & - & $1.1 \%$ & $0.7 \%$ & $64 \%$ \\
\hline & B & $1.6 \%$ & $8.9 \%$ & $10.6 \%$ & - & - & $7.0 \%$ & $1.8 \%$ & $26 \%$ \\
\hline \multirow{2}{*}{ SH0.8 } & A & $3.2 \%$ & $3.1 \%$ & $5.8 \%$ & - & - & $4.0 \%$ & $1.0 \%$ & $24 \%$ \\
\hline & B & $4.6 \%$ & $9.9 \%$ & $11.5 \%$ & - & - & $8.7 \%$ & $1.5 \%$ & $18 \%$ \\
\hline
\end{tabular}

A: Proposed model with tension softening and residual stiffness effect. B: FE model without TS (without tension softening and residual stiffness effect).

The variables examined herein are the applied load, $P$, or the deformation, $\delta$ (Table 5 ), the tangent stiffness, $K_{\text {tan }}$ (Table 6), the secant stiffness, $K_{\text {sec }}$ (Table 7) and the cyclic stiffness, $K_{\text {cyclic }}$ (Table 8 ). Each table summarizes the mean absolute error (MAE), the standard error (SE) and the coefficient of variation $(\mathrm{CV})$ of the examined variable for each beam. 
Table 6. Error calculation in the prediction of tangent stiffness, $K_{t a n}$.

\begin{tabular}{|c|c|c|c|c|c|c|c|c|c|c|c|c|c|c|}
\hline \multirow{3}{*}{$\begin{array}{l}\text { Beam } \\
\text { Name }\end{array}$} & & \multicolumn{10}{|c|}{ MAE at Each Cycle } & \multirow{3}{*}{$\begin{array}{c}\text { Overall } \\
\text { MAE }\end{array}$} & \multirow{3}{*}{ SE } & \multirow{3}{*}{$\mathrm{CV}$} \\
\hline & & \multicolumn{2}{|c|}{ Cycle 1} & \multicolumn{2}{|c|}{ Cycle 2} & \multicolumn{2}{|c|}{ Cycle 3} & \multicolumn{2}{|c|}{ Cycle 4} & \multicolumn{2}{|c|}{ Cycle 5} & & & \\
\hline & & $K_{\tan }^{(+)}$ & $K_{\tan }^{(-)}$ & $K_{\tan }^{(+)}$ & $K_{\tan }^{(-)}$ & $K_{t a n}^{(+)}$ & $K_{\tan }^{(-)}$ & $K_{\tan }^{(+)}$ & $K_{\tan }^{(-)}$ & $K_{\tan }^{(+)}$ & $K_{\tan }^{(-)}$ & & & \\
\hline \multirow{2}{*}{ FL0.3 } & A & $1.8 \%$ & $3.5 \%$ & $8.3 \%$ & $14.2 \%$ & $6.0 \%$ & $6.1 \%$ & - & - & - & - & $6.7 \%$ & $1.6 \%$ & $24.3 \%$ \\
\hline & B & $31.8 \%$ & $41.5 \%$ & $30.5 \%$ & $28.4 \%$ & $35.8 \%$ & $24.5 \%$ & - & - & - & - & $32.1 \%$ & $2.0 \%$ & $6.1 \%$ \\
\hline \multirow{2}{*}{ FL1.0 } & A & $5.9 \%$ & $4.4 \%$ & $21.6 \%$ & $13.3 \%$ & $4.1 \%$ & $11.7 \%$ & - & - & - & - & $10.2 \%$ & $2.4 \%$ & $24.0 \%$ \\
\hline & B & $25.6 \%$ & $30.9 \%$ & $17.4 \%$ & $13.2 \%$ & $16.1 \%$ & $19.0 \%$ & - & - & - & - & $20.4 \%$ & $2.5 \%$ & $12.5 \%$ \\
\hline \multirow{2}{*}{ SH0.3-s37 } & A & $5.4 \%$ & $6.4 \%$ & $3.2 \%$ & $12.5 \%$ & $1.1 \%$ & $8.0 \%$ & $9.2 \%$ & $6.6 \%$ & $6.6 \%$ & $8.3 \%$ & $6.7 \%$ & $1.3 \%$ & $18.8 \%$ \\
\hline & B & $5.7 \%$ & $8.8 \%$ & $4.7 \%$ & $12.0 \%$ & $16.8 \%$ & $6.7 \%$ & $23.0 \%$ & $14.0 \%$ & $23.8 \%$ & $20.6 \%$ & $13.6 \%$ & $1.7 \%$ & $12.6 \%$ \\
\hline \multirow{2}{*}{ SH0.3-s50 } & A & $8.8 \%$ & $11.5 \%$ & $4.8 \%$ & $11.7 \%$ & $9.3 \%$ & $5.1 \%$ & $9.4 \%$ & $6.2 \%$ & $13.3 \%$ & $1.3 \%$ & $8.1 \%$ & $1.0 \%$ & $12.6 \%$ \\
\hline & B & $8.0 \%$ & $8.0 \%$ & $7.2 \%$ & $10.4 \%$ & $23.0 \%$ & $18.6 \%$ & $26.7 \%$ & $16.7 \%$ & $23.4 \%$ & $19.9 \%$ & $16.2 \%$ & $1.9 \%$ & $12.0 \%$ \\
\hline \multirow{2}{*}{ SH0.3 } & A & $4.5 \%$ & $9.3 \%$ & $7.2 \%$ & $23.1 \%$ & $10.8 \%$ & $6.1 \%$ & - & - & - & - & $10.1 \%$ & $2.9 \%$ & $28.7 \%$ \\
\hline & B & $3.5 \%$ & $7.4 \%$ & $9.2 \%$ & $14.1 \%$ & $3.8 \%$ & $9.9 \%$ & - & - & - & - & $8.0 \%$ & $2.1 \%$ & $26.2 \%$ \\
\hline \multirow{2}{*}{ SH0.4 } & A & $8.0 \%$ & $5.4 \%$ & $14.2 \%$ & $6.2 \%$ & $7.5 \%$ & $24.3 \%$ & - & - & - & - & $10.9 \%$ & $2.5 \%$ & $22.5 \%$ \\
\hline & B & $8.0 \%$ & $6.1 \%$ & $22.7 \%$ & $9.8 \%$ & $20.2 \%$ & $30.3 \%$ & - & - & - & - & $16.2 \%$ & $3.1 \%$ & $19.2 \%$ \\
\hline \multirow{2}{*}{ SH0.6 } & A & $14.8 \%$ & $10.4 \%$ & $17.6 \%$ & $7.0 \%$ & $6.5 \%$ & $8.4 \%$ & - & - & - & - & $10.8 \%$ & $1.5 \%$ & $14.1 \%$ \\
\hline & B & $13.4 \%$ & $10.4 \%$ & $23.0 \%$ & $11.1 \%$ & $12.4 \%$ & $21.5 \%$ & - & - & - & - & $15.3 \%$ & $2.0 \%$ & $13.1 \%$ \\
\hline \multirow{2}{*}{ SH0.8 } & A & $12.9 \%$ & $7.4 \%$ & $11.0 \%$ & $18.2 \%$ & $10.4 \%$ & $6.9 \%$ & - & - & - & - & $11.2 \%$ & $2.3 \%$ & $20.4 \%$ \\
\hline & B & $12.9 \%$ & $9.2 \%$ & $16.2 \%$ & $6.2 \%$ & $11.7 \%$ & $7.2 \%$ & - & - & - & - & $10.6 \%$ & $2.2 \%$ & $20.9 \%$ \\
\hline
\end{tabular}

A: Proposed model with tension softening and residual stiffness effect. B: FE model without TS (without tension softening and residual stiffness effect). 
Table 7. Error calculation in the prediction of secant stiffness, $K_{s e c}$.

\begin{tabular}{cccccccccc}
\hline \multirow{2}{*}{ Beam Name } & & \multicolumn{9}{c}{ MAE at Each Cycle } & \multicolumn{2}{c}{ Overall } & \multirow{2}{*}{ SE } & CV \\
& & Cycle 1 & Cycle 2 & Cycle 3 & Cycle 4 & Cycle 5 & MAE & & \\
\hline \multirow{2}{*}{ FL0.3 } & A & $4.7 \%$ & $1.8 \%$ & $4.0 \%$ & - & - & $3.5 \%$ & $1.0 \%$ & $28.2 \%$ \\
& B & $25.9 \%$ & $36.1 \%$ & $29.7 \%$ & - & - & $30.6 \%$ & $1.9 \%$ & $6.2 \%$ \\
FL1.0 & A & $8.3 \%$ & $12.5 \%$ & $4.1 \%$ & - & - & $8.3 \%$ & $1.8 \%$ & $21.5 \%$ \\
& B & $22.1 \%$ & $1.9 \%$ & $12.0 \%$ & - & - & $12.0 \%$ & $4.3 \%$ & $35.9 \%$ \\
SH0.3-s37 & A & $4.8 \%$ & $0.4 \%$ & $4.0 \%$ & $8.1 \%$ & $11.1 \%$ & $5.7 \%$ & $1.7 \%$ & $30.1 \%$ \\
& B & $5.8 \%$ & $8.0 \%$ & $15.9 \%$ & $19.4 \%$ & $20.5 \%$ & $13.9 \%$ & $2.8 \%$ & $19.9 \%$ \\
SH0.3-s50 & A & $7.4 \%$ & $1.9 \%$ & $6.2 \%$ & $12.8 \%$ & $10.0 \%$ & $7.7 \%$ & $1.7 \%$ & $21.8 \%$ \\
& B & $4.0 \%$ & $12.0 \%$ & $23.0 \%$ & $26.0 \%$ & $27.9 \%$ & $18.6 \%$ & $3.4 \%$ & $18.3 \%$ \\
SH0.3 & A & $3.9 \%$ & $4.4 \%$ & $2.8 \%$ & - & - & $3.7 \%$ & $1.4 \%$ & $37.6 \%$ \\
& B & $2.6 \%$ & $5.4 \%$ & $11.0 \%$ & - & - & $6.3 \%$ & $2.1 \%$ & $33.4 \%$ \\
SH0.4 & A & $2.9 \%$ & $3.0 \%$ & $5.4 \%$ & - & - & $3.8 \%$ & $0.7 \%$ & $19.0 \%$ \\
& B & $4.4 \%$ & $11.4 \%$ & $18.4 \%$ & - & - & $11.4 \%$ & $2.8 \%$ & $24.3 \%$ \\
SH0.6 & A & $0.9 \%$ & $2.9 \%$ & $2.9 \%$ & - & - & $2.3 \%$ & $0.7 \%$ & $30.7 \%$ \\
& B & $2.3 \%$ & $7.7 \%$ & $7.7 \%$ & - & - & $5.9 \%$ & $1.5 \%$ & $25.1 \%$ \\
SH0.8 & A & $3.3 \%$ & $3.0 \%$ & $3.5 \%$ & - & - & $3.3 \%$ & $0.5 \%$ & $15.3 \%$ \\
& B & $2.2 \%$ & $9.0 \%$ & $8.5 \%$ & - & - & $6.6 \%$ & $1.6 \%$ & $23.8 \%$ \\
\hline
\end{tabular}

A: Proposed model with tension softening and residual stiffness effect. B: FE model without TS (without tension softening and residual stiffness effect).

Table 8. Error calculation in the prediction of cyclic stiffness, $K_{c y c l i c}$.

\begin{tabular}{cccccccccc}
\hline \multirow{2}{*}{ Beam Name } & & \multicolumn{7}{c}{ MAE at Each Cycle } & \multicolumn{2}{c}{ Overall } & \multirow{2}{*}{ SE } & CV \\
& & Cycle 1 & Cycle 2 & Cycle 3 & Cycle 4 & Cycle 5 & MAE & & \\
\hline \multirow{2}{*}{ FL0.3 } & A & $4.6 \%$ & $1.8 \%$ & $1.0 \%$ & - & - & $2.5 \%$ & $1.1 \%$ & $44.2 \%$ \\
& B & $25.8 \%$ & $33.7 \%$ & $19.2 \%$ & - & - & $26.2 \%$ & $4.2 \%$ & $15.9 \%$ \\
FL1.0 & A & $8.2 \%$ & $12.4 \%$ & $0.3 \%$ & - & - & $7.0 \%$ & $3.5 \%$ & $50.6 \%$ \\
& B & $22.0 \%$ & $3.0 \%$ & $11.2 \%$ & - & - & $12.1 \%$ & $5.5 \%$ & $45.4 \%$ \\
SH0.3-s37 & A & $3.7 \%$ & $7.5 \%$ & $0.0 \%$ & $12.1 \%$ & $7.3 \%$ & $6.1 \%$ & $2.0 \%$ & $33.1 \%$ \\
& B & $2.1 \%$ & $2.8 \%$ & $15.4 \%$ & $22.9 \%$ & $22.5 \%$ & $13.1 \%$ & $4.6 \%$ & $34.8 \%$ \\
SH0.3-s50 & A & $7.0 \%$ & $1.9 \%$ & $5.2 \%$ & $12.5 \%$ & $9.9 \%$ & $7.3 \%$ & $1.8 \%$ & $25.2 \%$ \\
& B & $3.9 \%$ & $12.0 \%$ & $22.8 \%$ & $25.8 \%$ & $23.7 \%$ & $17.7 \%$ & $4.2 \%$ & $23.7 \%$ \\
SH0.3 & A & $3.8 \%$ & $3.4 \%$ & $1.7 \%$ & - & - & $3.0 \%$ & $0.7 \%$ & $22.0 \%$ \\
& B & $2.2 \%$ & $5.2 \%$ & $11.9 \%$ & - & - & $6.4 \%$ & $2.9 \%$ & $44.9 \%$ \\
SH0.4 & A & $2.0 \%$ & $6.3 \%$ & $5.8 \%$ & - & - & $4.7 \%$ & $1.3 \%$ & $28.5 \%$ \\
& B & $4.0 \%$ & $7.1 \%$ & $18.7 \%$ & - & - & $9.9 \%$ & $4.5 \%$ & $44.9 \%$ \\
SH0.6 & A & $0.4 \%$ & $0.5 \%$ & $1.6 \%$ & - & - & $0.8 \%$ & $0.4 \%$ & $45.4 \%$ \\
& B & $2.3 \%$ & $7.9 \%$ & $8.1 \%$ & - & - & $6.1 \%$ & $1.9 \%$ & $31.1 \%$ \\
SH0.8 & A & $0.0 \%$ & $2.9 \%$ & $3.7 \%$ & - & - & $2.2 \%$ & $1.1 \%$ & $50.2 \%$ \\
& B & $1.7 \%$ & $9.5 \%$ & $8.7 \%$ & - & - & $6.6 \%$ & $2.5 \%$ & $37.4 \%$ \\
\hline
\end{tabular}

A: Proposed model with tension softening and residual stiffness effect. B: FE model without TS (without tension softening and residual stiffness effect).

The overall MAE values in Tables 5-8 indicate that the proposed model predictions (Model A) lead to an error below $5.9 \%, 11.2 \%, 8.3 \%$ and $7.3 \%$ for $P$ or $\delta, K_{t a n}, K_{s e c}$ and $K_{c y c l i c}$, respectively, for each tested SFRC beam and the average MAE of all tested beams is $3.3 \%, 9.3 \%, 4.8 \%$ and $4.2 \%$, respectively, for the aforementioned variables. The corresponding average MAE of all tested beams for the same variables using the predictions of the FE model without tension softening; the stiffening effect (model B) is much higher and equal to $15.2 \%, 16.5 \%, 13.2 \%$ and $12.3 \%$, respectively. These average values of MAE clearly indicate that the developed FE analysis that takes into account the proposed model with tension softening for the tensional behavior of SFRC and residual stiffness effect yields to accurate predictions of the hysteretic response of concrete members reinforced with conventional reinforcement (bars and stirrups) and steel fibers. 


\subsection{Effect of Steel Fibers on the Hysteretic Response}

The influence of steel fibers on the cyclic response of flexural and shear-critical beams is demonstrated in this section through the hysteretic response of the tested specimens in terms of load versus deformation curves and cracking patterns. The experimental and the numerical hysteretic curves and the cracking patterns of the slender beams FL0.3 and FL1.0 are presented and compared in Figure 14. It is emphasized that SFRC beam FL1.0 with a higher content of steel fibers $(F=1.0$ and $V_{S F}=3 \%$ ) demonstrates higher strength, increased energy absorption capacity and improved cracking performance with less diagonal cracks formed at the shear spans, near the supports of the beam with regard to the SFRC beam FL0.3 with $F=0.3$ and $V_{S F}=1 \%$.
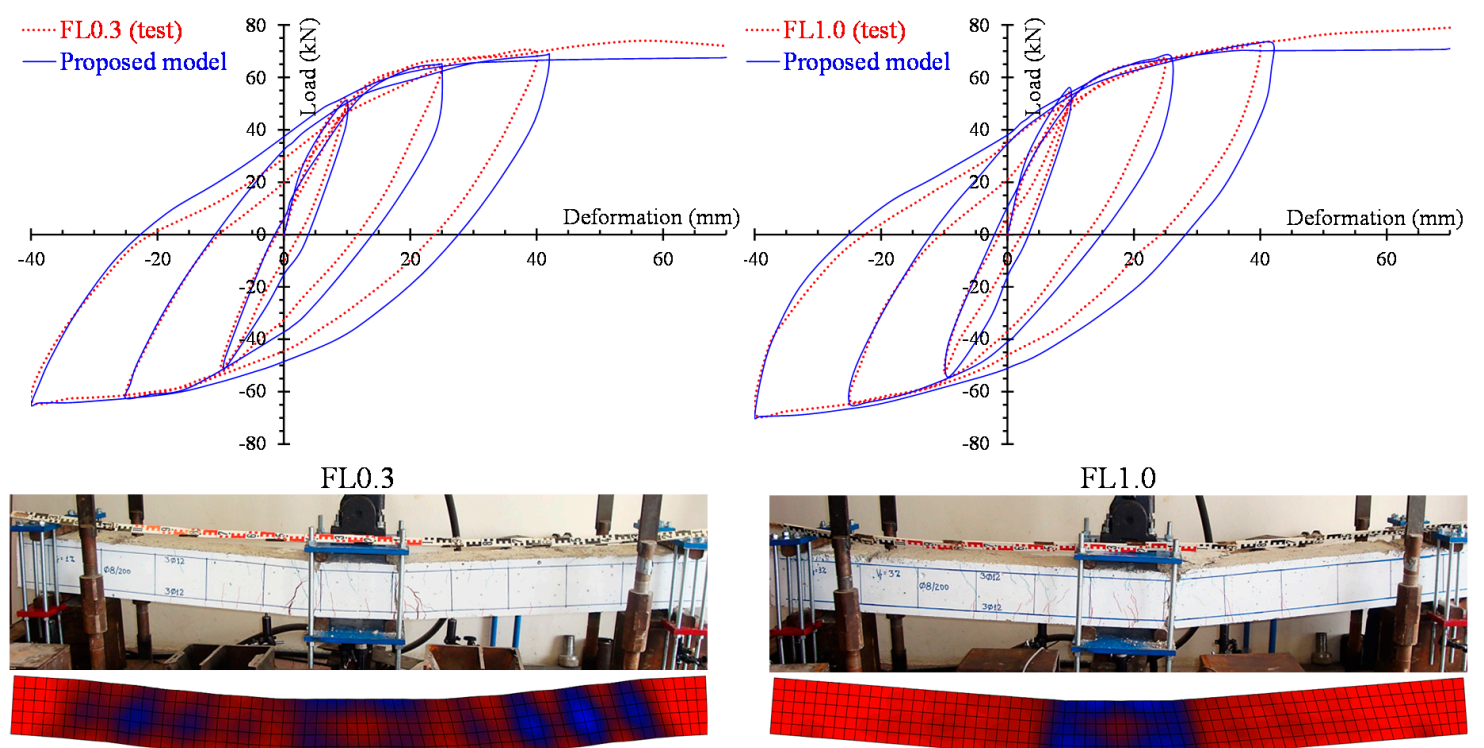

Figure 14. Full hysteretic response and cracking pattern at failure of the slender beams (group "FL" specimens).

The beneficial effect of the used steel fibers on the hysteretic performance is even more revealed and emphasized in the experimental results of the shear-critical beams. Figure 15 presents the load versus deformation curves per loading cycle of the beams of group "SH" (deep beams without stirrups). It is obvious that SFRC beams with a higher amount of steel fibers exhibit improved strength, stiffness and energy absorption capacity.

Furthermore, the gradual increase in the amount of the steel fibers added in the SFRC beams causes a consistent enhancement of the overall hysteretic response and the cracking performance of the deep beams without stirrups, as shown in Figure 16. Furthermore, the cracking patterns shown in Figure 16 indicate that less shear diagonal cracks have been formed in the SFRC beams with a higher amount of steel fibers. In particular, SFRC specimen SH0.8 with $F=0.8$ and $V_{S F}=1.5 \%$ exhibited more and wide flexural cracks, whereas only slight diagonal cracks have been developed in the shear spans of the beam. On the contrary, plain concrete beam SH0 and SFRC beam SH0.3 with a low amount of steel fibers $\left(F=0.3\right.$ and $V_{S F}=0.5 \%$ ) demonstrated severe shear diagonal cracks and quite brittle behavior.

More or less, similar concluding remarks are also deduced from the comparisons of the hysteretic and cracking performance of the tested deep beams with stirrups (Figure 17). Beams with steel fibers, even in low amounts ( $F=0.3$ and $V_{S F}=0.5 \%$ ) demonstrated improved overall behavior and especially cracking patterns with less severe shear diagonal cracks than the corresponding plain concrete beams. 


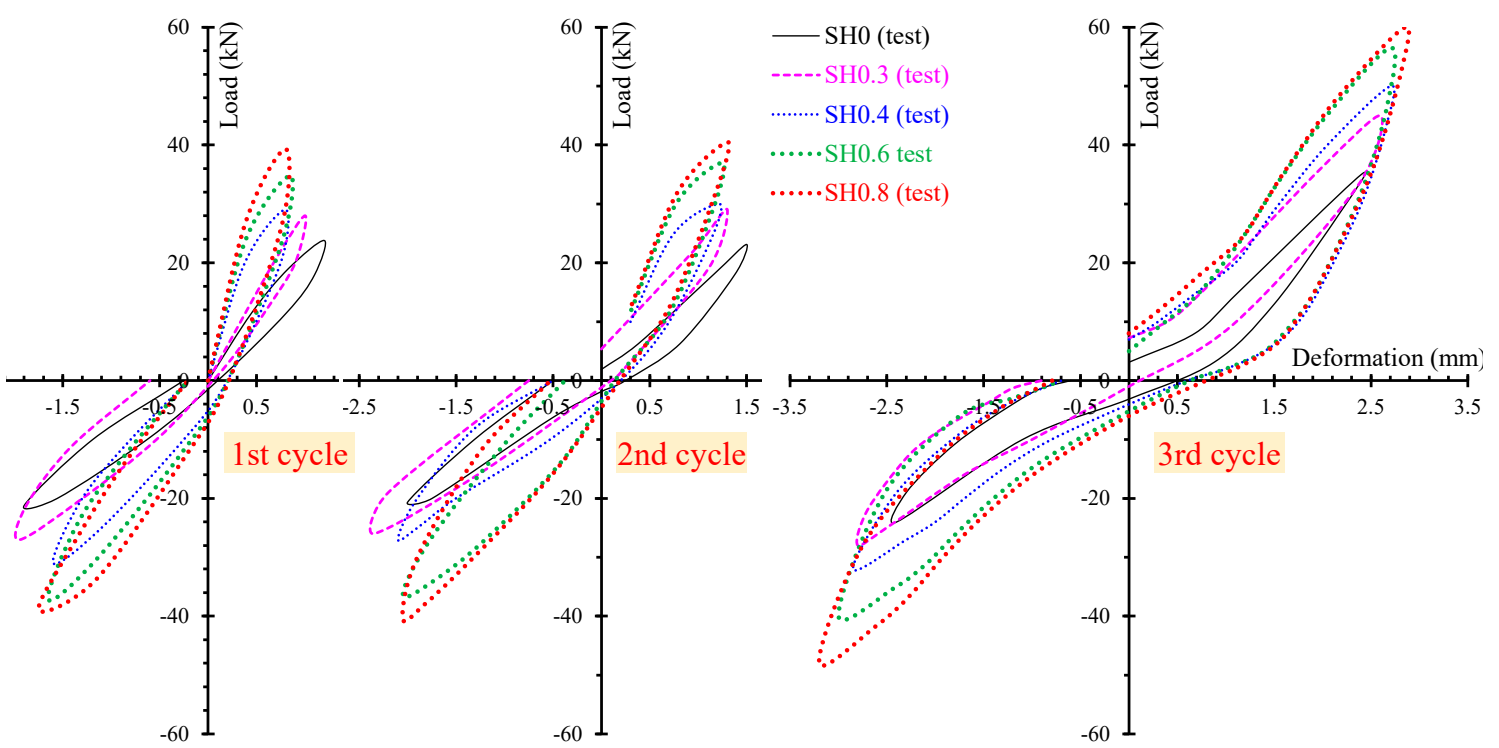

Figure 15. Hysteretic response at each loading cycle of the shear-critical beams without stirrups (group "SH" specimens).

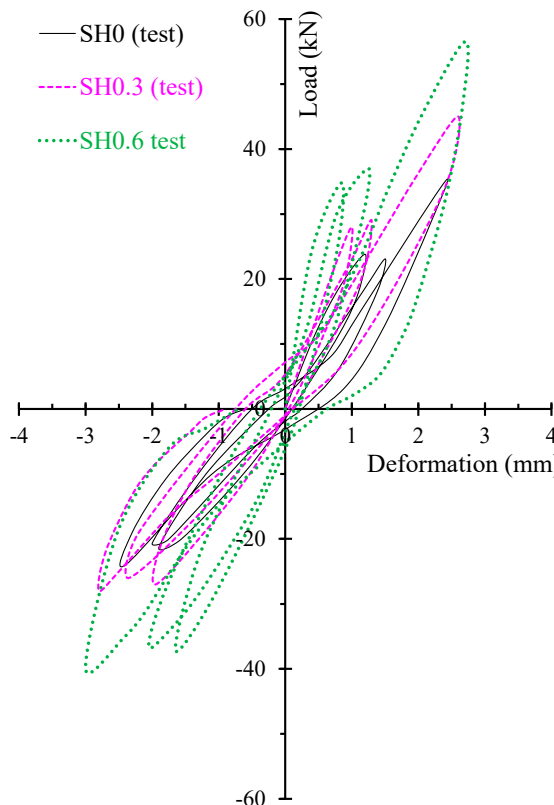

$-601$
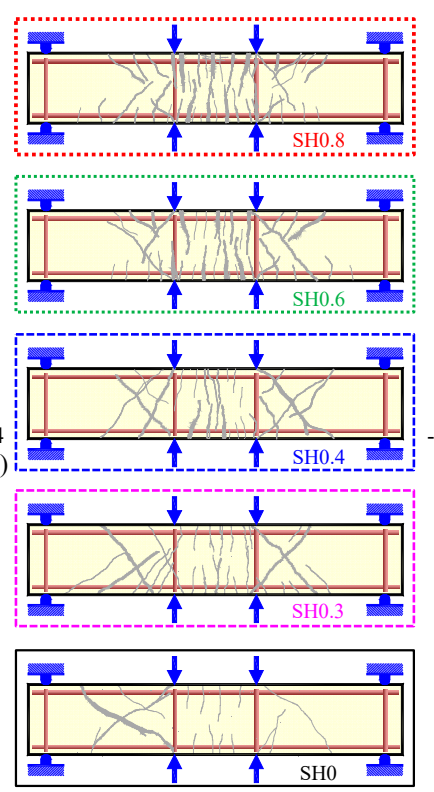

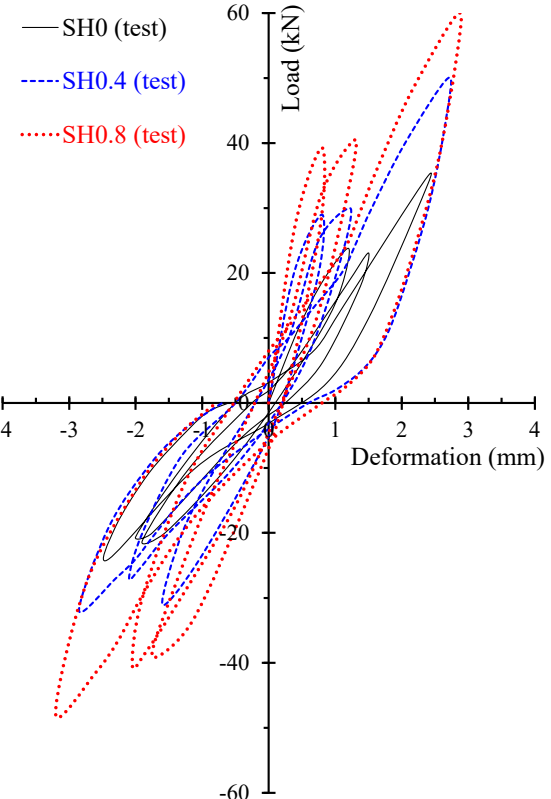

$-601$

Figure 16. Influence of the steel fibers on the hysteretic and cracking behavior of the shear-critical beams without stirrups (group "SH" specimens).

Furthermore, the improvement of the hysteretic response due to the addition of steel fibers is also indicated in the ratios of the cumulative total energy absorbed per loading cycle of each SFRC beam summarized in Table 9. These ratios have been evaluated from the area enclosed within a full loading cycle of every cycle of the SFRC beam divided by the area of the same cycle of the corresponding reference plain concrete beam (without steel fibers). The absorbed energy reflects the capacity and toughness of the beam.

The results presented in Table 9 indicate that SFRC deep beams absorbed a substantially larger amount of energy than the beams without steel fibers since the ratios are much greater than 1.0. Although this improvement seems to be lower in the slender beams, the ability of fibers to enhance cyclic loading conditions is profound. Thus, SFRC beams maintain their integrity through a potential 
seismic excitation exhibiting higher energy dissipation capacities than the corresponding beams without steel fibers.
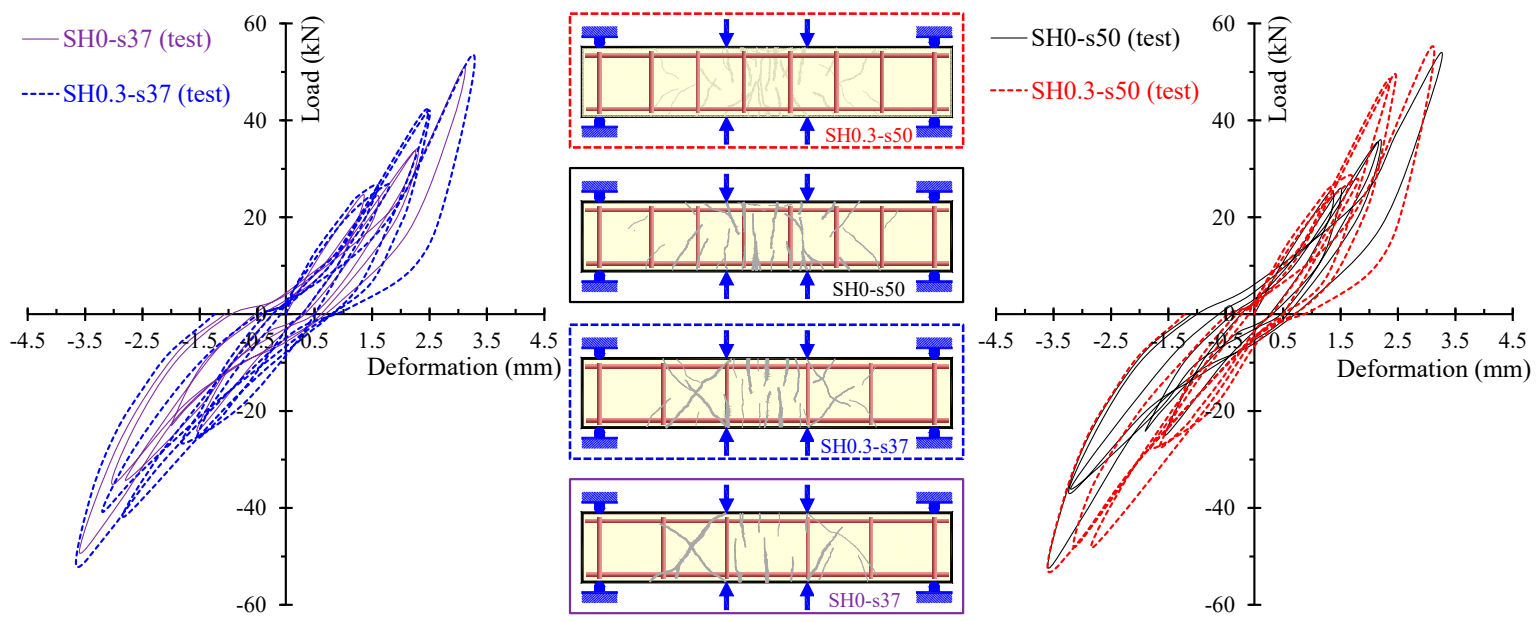

Figure 17. Influence of the steel fibers on the hysteretic and cracking behavior of the shear-critical beams with stirrups (group "SH-s" specimens).

Table 9. Energy dissipation ratios.

\begin{tabular}{cccccccccc}
\hline Group & $\begin{array}{c}\text { Beam } \\
\text { Name }\end{array}$ & $\boldsymbol{F}$ & $\begin{array}{l}\boldsymbol{V}_{\text {SF }} \\
\mathbf{( \% )}\end{array}$ & $\begin{array}{c}\boldsymbol{\rho}_{\boldsymbol{w}} \\
\mathbf{( \% )}\end{array}$ & Cycle 1 & Cycle 2 & Cycle 3 & Cycle 4 & Cycle 5 \\
\hline \multirow{2}{*}{ "FL" } & FL0.3 & 0.3 & 1.00 & 0.25 & 1.00 & 1.17 & 1.09 & - & - \\
& FL1.0 & 1.0 & 3.00 & 0.25 & 1.00 & 1.28 & 1.20 & - & - \\
\hline \multirow{2}{*}{ “SH-s" } & SH0.3-s37 & 0.3 & 0.50 & 0.37 & 1.33 & 1.80 & 1.59 & 1.26 & 1.49 \\
& SH0.3-s50 & 0.3 & 0.50 & 0.50 & 1.42 & 1.73 & 1.40 & 1.21 & 1.27 \\
\hline \multirow{2}{*}{ "SH" } & SH0.3 & 0.3 & 0.50 & - & 1.38 & 1.60 & 1.60 & - & - \\
& SH0.4 & 0.4 & 0.75 & - & 1.40 & 1.67 & 2.40 & - & - \\
& SH0.6 & 0.6 & 1.00 & - & 1.73 & 2.08 & 3.09 & - & - \\
& SH0.8 & 0.8 & 1.50 & - & 1.98 & 2.55 & 3.47 & - & - \\
\hline
\end{tabular}

The effectiveness of steel fibers as the only shear reinforcement, as an alternative of conventional steel stirrups is examined in Figure 18. This figure illustrates and compares the hysteretic and cracking behavior of the SFRC deep beam SH0.8 $\left(V_{S F}=1.5 \%\right)$ without stirrups and the plain concrete deep beams $\mathrm{SH} 0$-s37 and $\mathrm{SH} 0-\mathrm{s} 50$ with stirrups ratio $\rho_{w}=0.37 \%$ and $0.50 \%$, respectively. From the comparison of the load versus deformation curves, it is deduced that the SFRC beam without stirrups exhibited, more or less, a comparable hysteretic response with the RC beams with stirrups. Thus, a potential replacement of stirrups with steel fibers could be achieved under certain circumstances.

These specific conditions depend on the ability of an SFRC beam with longitudinal bars to satisfy pre-set strength and ductility requirements that are defined by design criteria. The optimum amount of the steel fibers that should be added in the mixture of the beam can be evaluated using a recently proposed analytical methodology by Chalioris [92]. Based on this approach, steel fibers as the only shear reinforcement or a desirable combination of steel fibers and stirrups can be used to achieve the above requirement. The methodology is based on the fact that the desirable flexural failure mode occurs when the shear resistance of the examined SFRC beam is higher than its ultimate flexural strength. Analytical expressions to calculate the flexural and the shear strength of SFRC structural members are implemented. A formula to evaluate the minimum steel fibers required in terms of the fiber factor, $F$, has also been addressed in order for the examined SFRC beam to demonstrate pure flexural response with adequate strength and ductility, whereas its validity has been checked by the 
test data of 256 SFRC beams under monotonic loading from the literature [92]. However, more cyclic tests are required to provide sound conclusions concerning this important issue.

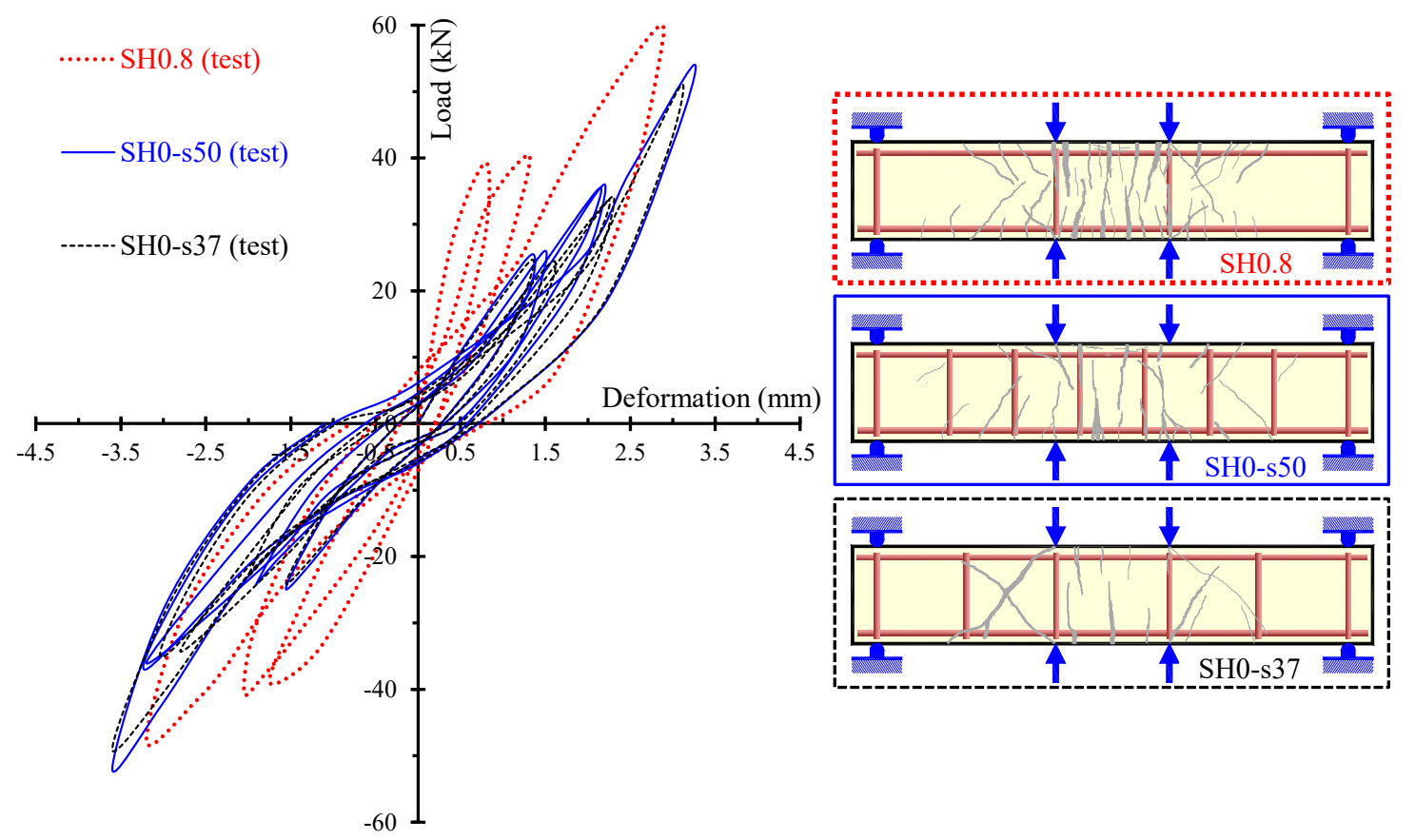

Figure 18. Potential replacement of common closed steel stirrups with short steel fibers.

\section{Conclusions}

The efficiency of steel fibers on the hysteretic performance of realistic flexural and shear-critical steel fiber-reinforced concrete (SFRC) beams reinforced with steel reinforcements has been investigated. An experimental program of eleven beam specimens subjected to reversal cyclic loading and a numerical nonlinear finite element (FE) analysis have been presented. Based on the results of this study, the following concluding remarks can be drawn:

- The performed cyclic loading tests of slender and deep beams indicate that SFRC beams with increased values of the fiber factor, $F$, exhibit an improved hysteretic response in terms of stiffness, load-bearing capacity, deformation, energy dissipation ability and cracking behavior. The favorable effect of the used steel fibers on the overall seismic response has been highlighted since SFRC specimens maintain their integrity through the imposed reversal cyclic tests exhibiting higher values of load-bearing capacity and cumulative energy absorbed per loading cycle than the corresponding plain concrete beams without fibers. It is noted that steel fibers with a volume fraction of $1 \%$ and $3 \%$ provided a $17 \%$ and $28 \%$ increase in the energy dissipation, respectively, for the case of the flexural beams. This increase was much higher in the shear-critical beams without stirrups. In particular, the ratio of the cumulative energy absorbed of the last loading cycle of the SFRC deep beams to the corresponding energy of the reference plain concrete beams was 1.60, 2.40, 3.09 and 3.47 for beams with fiber factor $F=0.3,0.4,0.6$ and 0.8 , respectively.

- Shear-critical beams reinforced with longitudinal bars and steel fibers without stirrups exhibited comparable hysteretic response in terms of strength and absorbed energy with the corresponding deep beams reinforced with bars and stirrups without steel fibers. Although more tests are still required to provide wide-ranging conclusions, it is indicated that a potential replacement of stirrups with steel fibers could be achieved under certain circumstances that depend on the ability of the SFRC beam to satisfy pre-set strength and ductility requirements.

- The developed FE simulation considers the nonlinearities of the materials by a smeared crack approach with tension softening and residual stiffness effect. The favorable influence of the steel 
fibers is evaluated according to their characteristics and content in order to achieve a more realistic prediction of SFRC behavior under compression and tension.

- The direct tension experimental results of SFRC specimens carried out in this study verify the analytical predictions of the proposed tensional model. These tests indicate that steel fibers substantially improve the post-cracking tensile behavior and the residual stress versus crack width curve according to the values of the fiber factor, $F$. Specifically, the value of the maximum post-cracking residual tensile stress was found to be $0.22,0.33,0.40$ and 0.57 times the value of the tensile strength for SFRC mixtures with fiber factor $F=0.3,0.4,0.6$ and 0.8 , respectively. Furthermore, this fiber factor is a more efficient parameter than the volume fraction for the evaluation of the steel fiber contribution.

- The developed nonlinear FE analysis accurately predicts the overall hysteretic response and points out the beneficial effect of the added fibers. Comparisons between the test and numerical results reveal that the developed nonlinear FE analysis with a smeared crack model that takes into account the tension softening and residual stiffness effect accurately predicts the hysteretic response of realistic SFRC beams with steel reinforcement. Furthermore, its validity and accuracy have been checked by calculating the discrepancies between test data and numerical predictions for various variables, such as load, deformation, and stiffness. The mean absolute errors of these variables were found to be satisfactorily low for the tested beams.

Author Contributions: All authors contributed extensively to this study, discussed the results and reviews, and agreed to the amendments at all stages of the paper. C.E.C. and C.G.K. designed and performed the tests. V.K.K. and C.E.C. analyzed the test results, developed the aspects of the experimental investigation and prepared the manuscript. V.K.K. developed the aspects of the numerical investigation and performed the FE analyses under the supervision of C.E.C., C.G.K. and A.E. All authors have read and agreed to the published version of the manuscript.

Funding: This research received no external funding.

Acknowledgments: Author Violetta K. Kytinou gratefully acknowledges the financial support received from Eugenides Foundation towards doctoral studies.

Conflicts of Interest: The authors declare no conflict of interest.

\section{References}

1. Conforti, A.; Zerbino, R.; Plizzari, G.A. Influence of steel, glass and polymer fibers on the cracking behavior of reinforced concrete beams under flexure. Struct. Concr. 2019, 20, 133-143. [CrossRef]

2. Smarzewski, P. Effect of curing period on properties of steel and polypropylene fibre reinforced ultra-high performance concrete. Mater. Sci. Eng. 2017, 245, 032059. [CrossRef]

3. Bencardino, F.; Nisticò, M.; Verre, S. Experimental investigation and numerical analysis of bond behavior in SRG-strengthened masonry prisms using UHTSS and stainless-steel fibers. Fibers 2020, 8, 8. [CrossRef]

4. Cuenca, E.; Ferrara, L. Self-healing capacity of fiber reinforced cementitious composites. State of the art and perspectives. KSCE J. Civ. Eng. 2017, 21, 2777-2789. [CrossRef]

5. Guerini, V.; Conforti, A.; Plizzari, G.; Kawashima, S. Influence of steel and macro-synthetic fibers on concrete properties. Fibers 2018, 6, 47. [CrossRef]

6. Martinelli, E.; Lima, C.; Pepe, M.; Caggiano, A.; Faella, C. Post-cracking response of hybrid recycled/industrial steel fiber-reinforced concrete. ACI Spec. Publ. 2018, 326, 64.1-64.10.

7. Belletti, B.; Cerioni, R.; Meda, A.; Plizzari, G. Design aspects on steel fiber-reinforced concrete pavements. J. Mater. Civ. Eng. 2008, 20, 599-607. [CrossRef]

8. Bencardino, F. Mechanical parameters and post-cracking behaviour of HPFRC according to three-point and four-point bending test. Adv. Civ. Eng. 2013, 2013, 179712. [CrossRef]

9. Caggiano, A.; Gambarelli, S.; Martinelli, E.; Nisticò, N.; Pepe, M. Experimental characterization of the post-cracking response in hybrid steel/polypropylene fiber-reinforced concrete. Constr. Build. Mater. 2016, 125, 1035-1043. [CrossRef]

10. Tsonos, A.-D.G. Steel fiber high-strength reinforced concrete: A new solution for earthquake strengthening of old R/C structures. WIT Trans. Built Env. 2009, 104, 153-164. 
11. Vougioukas, E.; Papadatou, M. A model for the prediction of the tensile strength of fiber-reinforced concrete members, before and after cracking. Fibers 2017, 5, 27. [CrossRef]

12. Abambres, M.; Lantsoght, E.O.L. ANN-Based Shear Capacity of Steel Fiber-Reinforced Concrete Beams without Stirrups. Fibers 2019, 7, 88. [CrossRef]

13. Campione, G.; Minafo, G. Behaviour of concrete deep beams with openings and low shear span-to-depth ratio. Eng. Struct. 2012, 41, 294-306. [CrossRef]

14. Ma, K.; Qi, T.; Liu, H.; Wang, H. Shear behavior of hybrid fiber reinforced concrete deep beams. Materials 2018, 11, 2023. [CrossRef]

15. Smarzewski, P. Analysis of failure mechanics in hybrid fibre-reinforced high-performance concrete deep beams with and without openings. Materials 2019, 12, 101. [CrossRef]

16. Cuenca, E.; Echegaray-Oviedo, J.; Serna, P. Influence of concrete matrix and type of fiber on the shear strength behavior of self-compacting fiber reinforced concrete. Compos. Part B Eng. 2015, 75, 135-147. [CrossRef]

17. Tsonos, A.-D.G. Ultra-high-performance fiber reinforced concrete: An innovative solution for strengthening old R/C structures and for improving the FRP strengthening method. WIT Trans. Eng. Sci. 2009, 64, 273-284.

18. Leone, M.; Centonze, G.; Colonna, D.; Micelli, F.; Aiello, M.A. Fiber-reinforced concrete with low content of recycled steel fiber: Shear behavior. Constr. Build. Mater. 2018, 161, 141-155. [CrossRef]

19. Cucchiara, C.; Mendola, L.; Papia, M. Effectiveness of stirrups and steel fibres as shear reinforcement. Cem. Concr. Compos. 2004, 26, 777-786. [CrossRef]

20. Zhao, J.; Liang, J.; Chu, L.; Shen, F. Experimental study on shear behavior of steel fiber reinforced concrete beams with high-strength reinforcement. Materials 2018, 11, 1682. [CrossRef]

21. Torres, J.A.; Lantsoght, E.O.L. Influence of fiber content on shear capacity of steel fiber-reinforced concrete beams. Fibers 2019, 7, 102. [CrossRef]

22. Tsonos, A.G.; Stylianidis, K. Seismic retrofit of beam-to-column joints with high-strength fiber jackets. Europ. Earthq. Eng. 2002, 16, 56-72.

23. Amato, G.; Campione, G.; Cavaleri, L.; Minafo, G. Flexural behaviour of external R/C steel fibre reinforced beam-column joints. Europ. J. Env. Civ. Eng. 2011, 15, 1253-1276. [CrossRef]

24. Kabir, M.R.; Alam, M.S.; Said, A.M.; Ayad, A. Performance of hybrid reinforced concrete beam column joint: A critical review. Fibers 2016, 4, 13. [CrossRef]

25. Abbas, A.A.; Mohsin, S.M.S.; Cotsovos, D.M. Seismic response of steel fiber reinforced concrete beam-column joints. Eng. Struct. 2014, 59, 261-283. [CrossRef]

26. Colajanni, P.; De Domenico, F.; Recupero, A.; Spinella, N. Concrete columns confined with fibre reinforced cementitious mortars: Experimentation and modelling. Constr. Build. Mater. 2014, 52, 375-384. [CrossRef]

27. Cascardi, A.; Longo, F.; Micelli, F.; Aiello, M.A. Compressive strength of confined column with fiber reinforced mortar (FRM): New design-oriented-models. Constr. Build. Mater. 2017, 156, 387-401. [CrossRef]

28. Chalioris, C.E.; Sfiri, E.F. Shear performance of steel fibrous concrete beams. Procedia Eng. 2011, 14, $2064-2068$. [CrossRef]

29. Chalioris, C.E.; Karayannis, C.G. Effectiveness of the use of steel fibers on the torsional behavior of flanged concrete beams. Cem. Concr. Compos. 2009, 31, 331-341. [CrossRef]

30. Spinella, N.; Colajanni, P.; Recupero, A. Simple plastic model for shear critical SFRC beams. J. Struct. Eng. 2010, 136, 390-400. [CrossRef]

31. Colajanni, P.; Recupero, A.; Spinella, N. Generalization of shear truss model to the case of SFRC beams with stirrups. Comput. Concr. 2012, 9, 227-244. [CrossRef]

32. Spinella, N. Shear strength of full-scale steel fibre-reinforced concrete beams without stirrups. Comput. Concr. 2013, 11, 365-382. [CrossRef]

33. Lantsoght, E.O.L. Database of shear experiments on steel fiber reinforced concrete beams without stirrups. Materials 2019, 12, 917. [CrossRef] [PubMed]

34. Bernat, A.M.; Spinella, N.; Recupero, A.; Cladera, A. Mechanical model for the shear strength of steel fiber reinforced concrete (SFRC) beams without stirrups. Mater. Struct. 2020, 53, 1-20.

35. Bischoff, P.H. Tension stiffening and cracking of steel fiber-reinforced concrete. ASCE J. Mat. Civ. Eng. 2003, 15, 174-182. [CrossRef]

36. Meskenas, A.; Kaklauskas, G.; Daniunas, A.; Bacinskas, D.; Jakubovskis, R.; Gribniak, V.; Gelazius, V. Determination of the stress-crack opening relationship of SFRC by an inverse analysis. Mech. Compos. Mater. 2014, 49, 685-690. [CrossRef] 
37. Morelli, F.; Amico, C.; Salvatore, W.; Squeglia, N.; Stacul, S. Influence of tension stiffening on the flexural stiffness of reinforced concrete circular sections. Materials 2017, 10, 669. [CrossRef]

38. Gribniak, V.; Arnautov, A.K.; Norkus, A.; Kliukas, R.; Tamulenas, V.; Gudonis, E.; Sokolov, A.V. Steel fibers: Effective way to prevent failure of the concrete bonded with FRP sheets. Adv. Mater. Sci. Eng. 2016, 2016, 10. [CrossRef]

39. Gribniak, V.; Tamulenas, V.; Ng, P.-L.; Arnautov, A.K.; Gudonis, E.; Misiunaite, I. Mechanical behavior of steel fiber-reinforced concrete beams bonded with external carbon fiber sheets. Materials 2017, 10, 666. [CrossRef]

40. Gribniak, V.; Ng, P.-L.; Tamulenas, V.; Misiunaite, I.; Norkus, A.; Šapalas, A. Strengthening of fibre reinforced concrete elements: Synergy of the fibres and external sheet. Sustainability 2019, 11, 4456. [CrossRef]

41. Meda, A.; Minelli, F.; Plizzari, G.A. Flexural behaviour of RC beams in fibre reinforced concrete. Compos. Part B Eng. 2012, 43, 2930-2937. [CrossRef]

42. Smarzewski, P. Flexural toughness of high-performance concrete with basalt and polypropylene short fibres. Adv. Civ. Eng. 2018, 2018, 5024353. [CrossRef]

43. Gribniak, V.; Kaklauskas, G.; Kwan, H.; Bacinskas, D.; lbinas, D. Deriving stress-strain relationships for steel fiber concrete in tension from tests of beams with ordinary reinforcement. Eng. Struct. 2012, 42, 387-395. [CrossRef]

44. Gribniak, V.; Kaklauskas, G.; Torres, L.; Daniunas, A.; Timinskas, E.; Gudonis, E. Comparative analysis of deformations and tension-stiffening in concrete beams reinforced with GFRP or steel bars and fibers. Compos. Part B Eng. 2013, 50, 158-170. [CrossRef]

45. Kaklauskas, G.; Gribniak, V.; Meskenas, A.; Bacinskas, D.; Juozapaitis, A.; Sokolov, A.; Ulbinas, D. Experimental investigation of the deformation behavior of SFRC beams with an ordinary reinforcement. Mech. Compos. Mater. 2014, 50, 417-426. [CrossRef]

46. Meskenas, A.; Gribniak, V.; Kaklauskas, G.; Sokolov, A.; Gudonis, E.; Rimkus, A. Experimental investigation of cracking behaviour of concrete beams reinforced with steel fibres produced in Lithuania. Baltic J. Road Bridge. Eng. 2017, 12, 82-87. [CrossRef]

47. Gribniak, V.; Arnautov, A.K.; Norkus, A.; Tamulenas, V.; Gudonis, E.; Sokolov, A. Experimental investigation of the capacity of steel fibers to ensure the structural integrity of reinforced concrete specimens coated with CFRP sheets. Mech. Compos. Mater. 2016, 52, 401-410. [CrossRef]

48. Ng, P.; Gribniak, V.; Jakubovskis, R.; Rimkus, A. Tension stiffening approach for deformation assessment of flexural reinforced concrete members under compressive axial load. Struct. Concr. 2019, 20, 2056-2068. [CrossRef]

49. Plizzari, G.A.; Cangiano, S.; Cere, N. Postpeak behavior of fiber-reinforced concrete under cyclic tensile loads. ACI Mater. J. 2000, 97, 182-192.

50. Graeff, A.G.; Pilakoutas, K.; Neocleous, K.; Peres, M.V.N.N. Fatigue resistance and cracking mechanism of concrete pavements reinforced with recycled steel fibres recovered from post-consumer tyres. Eng. Struct. 2012, 45, 385-395. [CrossRef]

51. Li, B.; Xu, L.; Chi, Y.; Huang, B.; Li, C. Experimental investigation on the stress-strain behavior of steel fiber reinforced concrete subjected to uniaxial cyclic compression. Constr. Build. Mater. 2017, 140, 109-118. [CrossRef]

52. Li, B.; Chi, Y.; Xu, L.; Li, C.; Shi, Y. Cyclic tensile behavior of SFRC: Experimental research and analytical model. Constr. Build. Mater. 2018, 190, 1236-1250. [CrossRef]

53. Gonzalez, D.C.; Vicente, M.A.; Ahmad, S. Effect of cyclic loading on the residual tensile strength of steel fiber-reinforced high-strength concrete. ASCE J. Mater. Civ. Eng. 2015, 27, 04014241. [CrossRef]

54. Daniel, L.; Loukili, A. Behavior of high-strength fiber-reinforced concrete beams under cyclic loading. ACI Struct. J. 2002, 99, 248-256.

55. Kotsovos, G.; Zeris, C.; Kotsovos, M. The effect of steel fibers on the earthquake-resistant design of reinforced concrete structures. Mater. Struct. 2007, 40, 175-188. [CrossRef]

56. Harajli, M.H.; Gharzeddine, O. Effect of steel fibers on bond performance of steel bars in NSC and HSC under load reversals. ASCE J. Mater. Civ. Eng. 2007, 19, 864-873. [CrossRef]

57. Campione, G.; Mangiavillano, M.L. Fibrous reinforced concrete beams in flexure: Experimental investigation, analytical modelling and design considerations. Eng. Struct. 2008, 30, 2970-2980. [CrossRef]

58. Tavallali, H.; Lepage, A.; Rautenberg, J.M.; Pujol, S. Concrete beams reinforced with high-strength steel subjected to displacement reversals. ACI Struct. J. 2014, 111, 1037-1048. [CrossRef] 
59. Caratelli, A.; Meda, A.; Rinaldi, Z. Monotonic and cyclic behaviour of lightweight concrete beams with and without steel fiber reinforcement. Constr. Build. Mater. 2016, 122, 23-35. [CrossRef]

60. Parra-Montesinos, G.J.; Chompreda, P. Deformation capacity and shear strength of fiber-reinforced cement composite flexural members subjected to displacement reversals. ASCE J. Struct. Eng. 2007, 133, 421-431. [CrossRef]

61. Luo, J.W.; Vecchio, F.J. Behavior of steel fiber-reinforced concrete under reversed cyclic shear. ACI Struct. J. 2016, 113, 75-84. [CrossRef]

62. Chalioris, C.E. Steel fibrous RC beams subjected to cyclic deformations under predominant shear. Eng. Struct. 2013, 49, 104-118. [CrossRef]

63. Rousakis, T.C.; Manolitsi, G.; Karabinis, A.I. FRP strengthening of RC columns: Parametric finite element analyses of bar quality effect. In Proceedings of the 1st Asia-Pacific Conference on FRP in Structures (APFIS 2007), Hong-Kong, China, 12-14 December 2007; Smith, S.T., Ed.; International Institute for FRP in Construction: Winnipeg, MB, Canada, 2007.

64. Gómez, J.; Torres, L.; Barris, C. Characterization and simulation of the bond response of NSM FRP reinforcement in concrete. Materials 2020, 13, 1770. [CrossRef]

65. Zhelyazov, T. Structural Materials: Identification of the constitutive models and assessment of the material response in structural elements strengthened with externally-bonded composite material. Materials 2020, 13, 1272. [CrossRef] [PubMed]

66. Chalioris, C.E.; Kosmidou, P.-M.K.; Karayannis, C.G. Cyclic response of steel fiber reinforced concrete slender beams: An experimental study. Materials 2019, 12, 1398. [CrossRef]

67. Dassault Systèmes Simulia System Information. In Abaqus 2017 User's Manual; Version 6.12.1; SIMULIA: Providence, RI, USA, 2017.

68. Lubliner, J.; Oliver, J.; Oller, S.; Oñate, E. A plastic-damage model for concrete. Int. J. Solids Struct. 1989, 25, 299-326. [CrossRef]

69. Karayannis, C.G. A numerical approach to steel-fibre reinforced concrete under torsion. Struct. Eng. Rev. 1995, 7, 83-91.

70. Lantsoght, E.O.L. How do steel fibers improve the shear capacity of reinforced concrete beams without stirrups? Compos. Part B Eng. 2019, 175, 107079. [CrossRef]

71. Yun,H.-D.; Lim, S.H.; Choi, W.-C. Effects of reinforcing fiber strength on mechanical properties of high-strength concrete. Fibers 2019, 7, 93. [CrossRef]

72. Neves, R.; Almeida, J. Compressive behaviour of steel fibre reinforced concrete. Struct. Concr. 2005, 6, 1-8. [CrossRef]

73. Bencardino, F.; Rizzuti, L.; Spadea, G. Stress-strain behavior of steel fiber-reinforced concrete in compression. ASCE J. Mater. Civ. Eng. 2008, 20, 255-263. [CrossRef]

74. Chalioris, C.E.; Liotoglou, F.A. Tests and simplified behavioral model for steel fibrous concrete under compression. In Advances in Civil Engineering and Building Materials IV.; Chang, S.-Y., Al Bahar, S.K., Husain, A.-A.M., Zhao, J., Eds.; CRC Press/Balkema: Leiden, The Netherlands, 2015; pp. 195-199.

75. Lee, S.-C.; Oh, J.-H.; Cho, J.-Y. Compressive behavior of fiber-reinforced concrete with end-hooked steel fibers. Materials 2015, 8, 1442-1458. [CrossRef] [PubMed]

76. Zhao, M.; Zhang, B.; Shang, P.; Fu, Y.; Zhang, X.; Zhao, S. Complete stress-strain curves of self-compacting steel fiber reinforced expanded-shale lightweight concrete under uniaxial compression. Materials 2019, 12, 2979. [CrossRef] [PubMed]

77. Chalioris, C.E.; Panagiotopoulos, T.A. Flexural analysis of steel fibre-reinforced concrete members. Comput. Concr. 2018, 22, 11-25.

78. Choi, W.-C.; Jung, K.-Y.; Jang, S.-J.; Yun, H.-D. The influence of steel fiber tensile strengths and aspect ratios on the fracture properties of high-strength concrete. Materials 2019, 12, 2105. [CrossRef]

79. Wang, Z.L.; Wu, J.; Wang, J.G. Experimental and numerical analysis on effect of fiber aspect ratio on mechanical properties of SFRC. Constr. Build. Mater. 2010, 24, 559-565. [CrossRef]

80. Choi, S.W.; Choi, J.; Lee, S.C. Probabilistic analysis for strain-hardening behavior of high-performance fiber-reinforced concrete. Materials 2019, 12, 2399. [CrossRef]

81. Bezerra, A.; Maciel, P.S.; Corrêa, E.; Soares Junior, P.R.R.; Aguilar, M.T.P.; Cetlin, P.R. Effect of high temperature on the mechanical properties of steel fiber-reinforced concrete. Fibers 2019, 7, 100. [CrossRef] 
82. Karayannis, C.G. Smeared crack analysis for plain concrete in torsion. ASCE J. Struct. Eng. 2000, 126, 638-645. [CrossRef]

83. Karayannis, C.G.; Chalioris, C.E. Experimental validation of smeared analysis for plain concrete in torsion. ASCE J. Struct. Eng. 2000, 126, 646-653. [CrossRef]

84. Rimkus, A.; Cervenka, V.; Gribniak, V.; Cervenka, J. Uncertainty of the smeared crack model applied to RC beams. Eng. Fract. Mech. 2020, 233, 107088. [CrossRef]

85. Kytinou, K.V.; Chalioris, C.E. Analysis of residual flexural stiffness of steel fiber-reinforced concrete beams with steel reinforcement. Materials 2020, 13, 2698. [CrossRef] [PubMed]

86. Karayannis, C.G. Nonlinear analysis and tests of steel-fiber concrete beams in torsion. Struct. Eng. Mech. 2000, 9, 323-338. [CrossRef]

87. Mudadu, A.; Tiberti, G.; Plizzari, G.A.; Morbi, A. Post-cracking behavior of polypropylene fiber reinforced concrete under bending and uniaxial tensile tests. Struct. Concr. 2019, 20, 1411-1424. [CrossRef]

88. Mudadu, A.; Tiberti, G.; Germano, F.; Plizzari, G.A.; Morbi, A. The effect of fiber orientation on the post-cracking behavior of steel fiber reinforced concrete under bending and uniaxial tensile tests. Cem. Concr. Compos. 2018, 93, 274-288. [CrossRef]

89. Bencardino, F.; Rizzuti, L.; Spadea, G.; Swamy, R.N. Experimental evaluation of fiber reinforced concrete fracture properties. Compos. Part B Eng. 2010, 41, 17-24. [CrossRef]

90. Bazant, Z.P.; Oh, B.H. Crack band theory for fracture of concrete. Mater. Constr. 1983, 16, 155-177. [CrossRef]

91. Genikomsou, A.S.; Polak, M.A. Finite element analysis of punching shear of concrete slabs using damaged plasticity model in ABAQUS. Eng. Struct. 2015, 98, 38-48. [CrossRef]

92. Chalioris, C.E. Analytical approach for the evaluation of minimum fiber factor required for steel fibrous concrete beams under combined shear and flexure. Constr. Build. Mater. 2013, 43, 317-336. [CrossRef]

(C) 2020 by the authors. Licensee MDPI, Basel, Switzerland. This article is an open access article distributed under the terms and conditions of the Creative Commons Attribution (CC BY) license (http://creativecommons.org/licenses/by/4.0/). 